\title{
Crash Aversion and the Cross-Section of Expected Stock Returns Worldwide
}

\author{
Florian Weigert * \\ First Version: October 2012 \\ This Version: December 2015
}

\begin{abstract}
This paper examines whether investors receive compensation for holding stocks with a strong sensitivity to extreme market downturns in a sample covering forty countries. Worldwide, stocks with strong crash sensitivity deliver average returns of more than $7 \%$ p.a. higher than stocks with weak crash sensitivity. The effect is robust across geographical subsamples and is not explained by systematic risk factors and alternative firm characteristics. I show that the risk premium is particularly pronounced in countries that display negative market skewness, high income per capita, and rank high on Hofstede's individualism index. (JEL G10, G12, G14, G20, G23)
\end{abstract}

${ }^{*}$ I thank Frédéric Délèze, Stefan Ruenzi, Sung Won Seo, Erik Theissen, and seminar participants at the European FMA 2013 Meeting, the Annual Conference of the Swiss Society for Financial Market Research 2013 conference, and the University of Mannheim for their helpful comments. All errors are my own. Send correspondence to Florian Weigert, Swiss Institute of Banking and Finance, University of St. Gallen, Rosenbergstrasse 52, 9000 St. Gallen, Switzerland; telephone: ++41-71-224-7014. E-mail: florian.weigert@unisg.ch. 


\title{
Crash Aversion and the Cross-Section of Expected Stock Returns Worldwide
}

\begin{abstract}
This paper examines whether investors receive compensation for holding stocks with a strong sensitivity to extreme market downturns in a sample covering forty countries. Worldwide, stocks with strong crash sensitivity deliver average returns of more than $7 \%$ p.a. higher than stocks with weak crash sensitivity. The effect is robust across geographical subsamples and is not explained by systematic risk factors and alternative firm characteristics. I show that the risk premium is particularly pronounced in countries that display negative market skewness, high income per capita, and rank high on Hofstede's individualism index. (JEL G10, G12, G14, G20, G23)
\end{abstract}


Since the pioneering work of Roy (1952), economists have recognized that individuals are aware of rare disaster events (e.g., stock market crashes) and take precautions to reduce their likelihood of being affected by such catastrophe. If agents derive disproportionately strong disutility from large financial losses, there should be a risk premium for the occurence of heavy tail events (Rietz 1988, Barro 2006, and Barro 2009). Indeed, Gabaix (2012) shows that a time-varying rare disaster risk framework can explain several puzzles in macro-finance and Bollerslev and Todorov (2011) find that the compensation for rare events accounts for a large fraction of the U.S. equity risk premium. ${ }^{1}$

In addition to explaining the development of aggregate stock market returns, rare disasters and crash aversion are shown to have an impact on the pricing of individual stocks in the cross-section. Chabi-Yo, Ruenzi, and Weigert (2015) theoretically show and empirically find that, in the U.S. setting, crash-sensitive stocks, that is, stocks that are likely to perform particularly badly when the market crashes, earn significantly higher average returns than crash-insensitive stocks, that is, stocks that offer some protection against market downturns. This finding is consistent with investors being particularly averse to suffering large financial losses during stock market crashes and thus requiring an additional return premium for holding such stocks. ${ }^{2}$

This paper examines the impact of investors' crash aversion on the cross-sectional pricing of individual stocks worldwide. First, I investigate whether stocks with strong crash sensitivity contemporaneously earn higher average returns than stocks with weak crash sensitivity in forty international stock markets. Second, I use differences in stock market and investor characteristics across countries to investigate the determinants of the crash sensitivity premium. Finally, I analyze whether an investable trading strategy based on the past information about a stock's crash sensitivity generates positive abnormal returns in the

\footnotetext{
${ }^{1}$ However, these findings are not without dissension. Julliard and Ghosh (2012) document that an equity premium puzzle of the same magnitude as the historical one is unlikely to arise, if aggregate stock market returns are generated by a rare events distribution.

${ }^{2}$ In related papers, Kelly and Jiang (2014) and Cholette and Lu (2011) show that there exists a premium for stocks with heavy tail risk exposure. They document that stocks with high systematic tail risk exposure earn significantly higher expected returns than stocks with low systematic tail risk exposure. Motivated by the underdiversified portfolio holdings of individual investors, Bali, Cakici, and Whitelaw (2014) introduce a new hybrid measure of stock return tail covariance risk and find that it predicts future stock returns.
} 
future.

Following the methodology of Chabi-Yo, Ruenzi, and Weigert (2015), I use copula methods based on extreme value theory to determine the crash sensitivity of a stock. Specifically, I capture the crash sensitivity of an individual stock based on the extreme dependence between the stock's daily return and the domestic daily market return in the lower left tail of their joint distribution (also called lower tail dependence, LTD) ${ }^{3}$

My empirical results indicate that a quintile portfolio consisting of stocks with the strongest LTD underperforms a quintile portfolio consisting of stocks with the weakest LTD by more than $9 \%$ on a monthly basis during periods of heavy market downturns worldwide. Consequently, from an equlilibrium perspective, investors who are sensitive to large losses during market crashes will require a premium for holding stocks with strong LTD in the long run. ${ }^{4}$

Investigating data from forty countries, I find strong support for a LTD risk premium in the cross-section of average stock returns. In the pooled worldwide sample, including U.S. stocks (excluding U.S. stocks) from 1981 to 2011, top quintile LTD stocks contemporaneously outperform bottom quintile LTD stocks by $7.35 \%$ (6.45\%) p.a. on average. The premium for LTD is positive and significant (at least at the $10 \%$ level) across all different geographical subsamples with a return spread between the strong LTD quintile portfolio and the weak LTD quintile portfolio ranging from $11.54 \%$ p.a. in the United States to $4.56 \%$ p.a. in Asia. Results from multivariate regression analysis reveal that the LTD premium cannot be explained by other risk- and firm characteristics, such as market beta (Sharpe 1964; Lintner 1965), size (Banz 1981), book-to-market (Basu 1983), liquidity (Amihud 2002), momentum (Jegadeesh and Titman 1993), idiosyncratic volatility (Ang et al. 2006, 2009), and coskewness (Harvey and Siddique 2000). Controlling for these variables, I find that a one-standard deviation in LTD is associated with an increase of average returns by $3.54 \%$ (2.45\%) p.a. based on the

\footnotetext{
${ }^{3}$ When focusing on joint extreme events of stock returns, the linear correlation is not the appropriate dependence concept. The linear correlation cannot capture joint extreme events if the underlying bivariate distribution is nonnormal (see Embrechts, McNeil, and Straumann 2002).

${ }^{4}$ Similar to the calculation of LTD, I also capture the extreme dependence between the stock's return and the market return in the upper right tail of their joint distribution (upper tail dependence, UTD). Stocks with strong UTD realize their highest payoffs in times of stock market booms, that is, they have high upside potential. Following the theoretical framework of Ang, Chen, and Xing (2006), investors are willing to hold stocks with high upside potential at a discount.
} 
worldwide sample, including the United States (excluding the United States). In line with the idea that investors overstate the fear of a future market crash when they can remember one (Gennaioli, Shleifer, and Vishny 2015), this premium is even higher in the three years following a large stock market downturn (see Section 2.3).

Although LTD has a strong positive impact on average stock returns, both in the pooled worldwide sample and in all geographical subsamples, there still exist large differences in the magnitude of the premium across countries. Separate examinations of each stock market reveal that the impact of LTD on average stock returns is significantly positive at the $10 \%$ level $(5 \%$ level, $1 \%$ level $)$ in $19(16,6)$ of the 40 countries. The largest return spreads between the top quintile LTD portfolio and the bottom quintile LTD portfolio are found in the United States (11.54\% p.a.), Australia (10.63\% p.a.), and the United Kingdom (9.92\% p.a.). Although not statistically significant, negative LTD premiums (i.e., LTD discounts) are found in China (-2.57\% p.a.), South Korea (-2.27\% p.a.), Taiwan (-1.61\% p.a.), the Philippines (-0.78\% p.a.), and Chile (-0.78\% p.a.).

How can one explain the large differences in the country-specific LTD premiums? My main hypotheses are that the premium for a stock's LTD is high in those countries in which stock market crashes are particularly severe and in which local stock market investors are likely to exhibit a high degree of crash aversion. ${ }^{5}$ Hence, to empirically tackle this question, I exploit differences in stock market characteristics, as well as investor characteristics and cultural attitudes that are likely to be correlated with investors' crash aversion across countries. I obtain the following results:

1. The LTD premium is significantly higher in countries with low (negative) market skewness. This finding is intuitive: if the market return is negatively skewed, the left tail of return observations is fatter than the right (positive) tail and extreme stock market downturns are particularly pronounced. To compensate for those severe market crashes, investors require a high compensation for a stock's LTD.

\footnotetext{
${ }^{5}$ I implicitly assume that most stocks in a country are held by local investors and that local investors hold a disproportional amount of their wealth in domestic assets. French and Poterba (1991) find strong empirical support for this so-called "home bias".
} 
2. The LTD premium is significantly higher in countries with high income per capita. This result is in line with Statman (2008), Rieger, Wang, and Hens (2015), and Paravisini, Rappoport, and Ravina (2015), who find that wealthier individuals tend to be more risk averse. ${ }^{6}$

3. The LTD premium is significantly higher in countries that rank high on the individualism index of Hofstede (2001). This result is consistent with Weber and Hsee (1998) and Hsee and Weber (1999), who document that people in individualistic countries tend to be more risk averse in financial decisions than people in collectivistic countries.

Finally, I analyze whether past LTD predicts the cross-section of future stock returns worldwide. I find that, for the majority of the cross-section, LTD has strong predictive power for future stock returns over the next month. However, this relationship collapses for stocks with high volatility. ${ }^{7}$ Predicting future LTD by past LTD is difficult for these stocks, because high volatility increases measurement error. As a result, the autocorrelation of one-year LTD coefficients is only 0.232 for high volatility stocks as compared to 0.405 for the remaining stocks. When excluding stocks with high volatility from the analysis, an investment strategy consisting of buying stocks with the strongest LTD and selling stocks with the weakest LTD at month $t$ earns a significantly positive average return of $0.40 \%$ $(0.37 \%)$ at month $t+1$ for the pooled worldwide sample including U.S. stocks (excluding U.S. stocks). Again, these results remain economically and statistically significant when controlling for systematic risk factors and firm characteristics.

My study is related to two strands of literature. First, I contribute to the literature on crash risk and asset pricing. Bali, Demirtas, and Levy (2009) examine the intertemporal relation between the univariate crash risk of a stock (measured by its value at risk (VaR), expected shortfall, and tail risk) and its expected return. They find a positive and significant

\footnotetext{
${ }^{6}$ However, this result on a positive relationship between wealth and risk attitudes is not without doubt: for example, Guiso and Paiella (2008) and Tanaka, Camerer, and Nguyen (2010) find a negative association between individuals' wealth and risk aversion.

${ }^{7}$ I consider a stock at month $t$ as highly volatile if its past one-year standard deviation is in the top decile among all stocks in the respective country.
} 
relationship between univariate crash risk and the returns on U.S. stocks. Ang, Chen, and Xing (2006) document a significant risk premium for stocks with a high downside beta, that is, stocks that have high betas conditional on market downturns. Chabi-Yo, Ruenzi, and Weigert (2015), Kelly and Jiang (2014) and Cholette and Lu (2011) investigate the impact of systematic crash risk on the cross-section of expected stock returns in the United States. They show that investors demand additional compensation for stocks that are crash-prone, that is, stocks that have particularly bad returns that coincide with market crashes. ${ }^{8}$ In a similar vein, Bali, Cakici, and Whitelaw (2014) develop a hybrid measure of stock return tail covariance risk and show that it predicts future stock returns with an annualized premium of $9 \%$. In this paper, I extend the literature by analyzing whether systematic crash risk is a priced factor among forty stock markets around the world.

Second, my paper contributes to the literature on the determinants of the cross-sectional variation in worldwide stock returns. Fama and French (1998) find that value stocks tend to have higher returns than growth stocks around the world. Furthermore, Griffin (2002) shows that country-specific versions of Fama and French's (1993) three-factor model better explain time-series variation in international stock returns than do global factor models. Griffin, Ji, and Martin (2003) document economically large and statistically signifcant momentum profits in a global setting and provide evidence that macroeconomic risk factors cannot explain those abnormal return patterns; instead, momentum strategy returns are influenced by cultural differences across countries (see Cui, Titman, and Wei 2010). Finally, Hou, Karolyi, and Kho (2011) provide evidence that a momentum factor and cash flow/price factor-mimicking portfolios, together with a global market factor, capture substantial common variation in international stock returns. ${ }^{9}$ This paper enhances the existing literature by investigating a new factor to explain the cross-section of stock returns worldwide - the crash sensitivity of a stock.

\footnotetext{
${ }^{8}$ Van Oordt and Zhou (forthcoming) use tail betas to measure crash risk of stocks but do not find evidence of higher returns associated with high tail betas.

${ }^{9}$ Galsband (2012) finds that differences in returns on value and growth portfolios in fourteen industrial countries can be rationalized by assets' sensitivities to the U.S. stock market's downside shocks.
} 


\section{Measuring Crash Sensitivity and Stock Market Data}

This part explains the methodology of how to capture the crash sensitivity of individual stocks (Section 1.1). I use copula methods to estimate the lower tail dependence (LTD) between individual stock returns and the market return. Subsequently, I describe the stock market data and the development of aggregate LTD over time (Section 1.2). Finally, I show that LTD captures the crash sensitivity of a stock by demonstrating that strong LTD portfolios heavily underperform weak LTD portfolios during financial crises worldwide (Section $1.3)$.

\subsection{Measuring crash sensitivity}

My approach to capturing the crash sensitivity of a stock follows the method of Chabi-Yo, Ruenzi, and Weigert (2015). I formalize the idea of capturing crash sensitivity by introducing the lower tail dependence (LTD) coefficient between an individual daily stock return $r_{i}$ and the domestic daily market return $r_{m}$, which is computed as the value-weighted average return of all stocks in the corresponding country. ${ }^{10}$ Following Sibuya (1960), LTD is defined as

$$
\operatorname{LTD}:=\operatorname{LTD}\left(r_{i}, r_{m}\right):=\lim _{u \rightarrow 0+} P\left(r_{i} \leq F_{i}^{-1}(u) \mid r_{m} \leq F_{m}^{-1}(u)\right)
$$

where $F_{i}\left(F_{m}\right)$ denotes the cumulative distribution function of stock return $r_{i}$ (the domestic

market return $\left.r_{m}\right)$ and $u \in(0,1)$ is the argument of the distribution function. Stocks with strong LTD are likely to have their lowest return realization at the same time when the market displays its lowest return realization, that is, these stocks are particularly sensitive to market crashes. As an example, consider the following two illustrations of 2,000 simulated bivariate realizations based on different dependence structures between $\left(r_{i}, r_{m}\right)$ shown in Figure 1.

[Insert Figure 1 about here]

\footnotetext{
${ }^{10}$ When computing the market return for stock $i$, I exclude stock $i$ in the computation. This approach removes potential endogeneity problems when calculating tail dependence coefficients for each stock.
} 
Panel A shows an example with no tail dependence in either tail of the distribution. In contrast, Panel B is an example of increased lower tail dependence (LTD).

Similarly, the coefficient of upper tail dependence (UTD) can be defined as

$$
\operatorname{UTD}:=\operatorname{UTD}\left(r_{i}, r_{m}\right)=\lim _{u \rightarrow 1-} P\left(r_{i} \geq F_{i}^{-1}(u) \mid r_{m} \geq F_{m}^{-1}(u)\right)
$$

Since LTD (UTD) is the limit of a conditional probability, it can take values between zero and one. If LTD (UTD) is equal to zero, the two variables are asymptotically independent in the lower (upper) tail.

I compute LTD and UTD coefficients in terms of a copula function $C$ fitted to the bivariate distribution of $\left(r_{i}, r_{m}\right) .{ }^{11}$ Following McNeil, Frey, and Embrechts (2005), simple expressions for LTD and UTD in terms of the copula $C$ of the bivariate distribution can be derived based on

$$
\operatorname{LTD}=\lim _{u \rightarrow 0+} \frac{C(u, u)}{u}
$$

and

$$
\mathrm{UTD}=\lim _{u \rightarrow 1-} \frac{1-2 u+C(u, u)}{1-u}
$$

if $F_{1}$ and $F_{2}$ are continuous. Equations (2) and (3) have closed-form solutions for many parametric copulas. In this study, I use twelve different basic copula functions. A detailed overview of these basic copulas and the corresponding lower tail dependencies (and upper tail dependencies) is given in Table A.1 in Appendix A.

Analogous to Chabi-Yo, Ruenzi, and Weigert (2015), I then form convex combinations of the basic copulas consisting of one copula (out of four) that allows for asymptotic dependence in the lower tail, $C_{\mathrm{LTD}}$, one copula (out of four) that is asymptotically independent, $C_{\mathrm{NTD}}$,

\footnotetext{
${ }^{11}$ Copula functions $C:[0,1]^{2} \mapsto[0,1]$ allow to isolate the dependence structure of the bivariate distribution from the univariate marginal distributions. Sklar (1959) shows that all bivariate distribution functions $F\left(x_{1}, x_{2}\right)$ can be completely described based on the univariate marginal distributions $F_{1}$ and $F_{2}$ and a copula function $C$.
} 
and one copula (out of four) that allows for asymptotic dependence in the upper tail, $C_{\mathrm{UTD}}$ :

$$
\begin{aligned}
C\left(u_{1}, u_{2}, \Theta\right)= & w_{1} \cdot C_{\mathrm{LTD}}\left(u_{1}, u_{2} ; \theta_{1}\right)+w_{2} \cdot C_{\mathrm{NTD}}\left(u_{1}, u_{2} ; \theta_{2}\right) \\
& +\left(1-w_{1}-w_{2}\right) \cdot C_{\mathrm{UTD}}\left(u_{1}, u_{2} ; \theta_{3}\right),
\end{aligned}
$$

where $\Theta$ denotes the set of the basic copula parameters $\theta_{i}, i=1,2,3$ and the convex weights $w_{1}$ and $w_{2}$.

To determine which convex copula combination best fits the bivariate distributions of individual stock returns $r_{i}$ and the domestic market return $r_{m}$ in a specific country, I use the first year of data available for each country as my pre-sample period. Based on daily return data, I fit all sixty-four possible convex copula combinations to the bivariate distribution of $\left(r_{i}, r_{m}\right)$ for all stocks $i$ in a country. I then select the respective copula combination $C^{*}\left(\cdot, \cdot ; \Theta^{*}\right)$ that is chosen most frequently based on the estimated log-likelihood value for each country. Table A.2 reports the results of this selection method.

Once the copula combination has been selected for each country, my estimation approach for the LTD and UTD coefficients follows a two-step procedure. First, for each stock $i$ and month $t$, I estimate the set of copula parameters $\Theta_{i, t}^{*}$ for the bivariate distribution of $\left(r_{i}, r_{m}\right)$ based on a rolling 12-month horizon using daily data. The copula parameters are estimated via the canonical maximum likelihood procedure of Genest, Ghoudi, and Rivest (1995). Second, for each stock $i$ and month $t$, I compute LTD and UTD coefficients implied by the estimated parameters $\Theta_{i, t}^{*}$ using Equations (2) and (3). Hence, I end with a panel of tail dependence coefficients $\operatorname{LTD}_{i, t}$ and $\mathrm{UTD}_{i, t}$ at the firm-month level. I use $\mathrm{LTD}_{i, t}\left(\mathrm{UTD}_{i, t}\right)$ as a proxy for the crash sensitivity (upward potential) of stock $i$ at month $t$. For a more detailed description of the estimation method, see Appendix A. 


\subsection{Stock market data and the evolution of aggregate LTD}

I obtain daily stock return and accounting data for the United States from CRSP and Compustat and daily stock return and accounting data for the remaining countries from Datastream International. The starting date for each country in my sample varies according to the availability of data on Datastream International with the earliest date (for some countries) being January 1980. ${ }^{12}$ I include all common stocks (both dead and alive) that are listed on the major stock exchanges in each country to circumvent any potential survivorship bias.

As discussed by Ince and Porter (2006), the quality of stock market data (in particular for emerging markets) obtained from Datastream International must be handled with care. Following Chui, Titman, and Wei (2010), I exclude very small and/or illiquid stocks. A daily return is treated as missing if the market capitalization of the stock is below the fifth percentile of all stocks within a given country on any day. In addition, to retain a stock in a given month, the stock must have at least five daily returns different from zero. To ensure that my results are not driven by extreme outliers in the data, daily returns are winsorized at the $1 \%$ level. I retain a stock in a given year if it has at least seventy daily nonmissing return observations. ${ }^{13}$ To obtain meaningful results in my portfolio sorts, all countries in the analysis must have at least thirty stocks that meet the stock selection criteria in any month during the sample period. In addition, all countries need to have monthly data on a stock's market capitalization and yearly data on a stock's book-to-market value for at least half of the stocks in the sample period.

My final sample consists of 49,409 individual stocks from forty different countries during the time period from January 1980 to December 2014. I estimate LTD (and UTD) coefficients for each firm and each month based on rolling windows of 12 months using daily data. Table 1 provides summary statistics.

\footnotetext{
${ }^{12}$ To be comparable with the international stock market data, I restrict the sample of U.S. stocks to begin with January 1980 as well. My U.S. sample consists of all common stocks (CRSP share codes 10 and 11) from CRSP trading on the NYSE and AMEX.

${ }^{13} \mathrm{My}$ results on the relationship between crash sensitivity and average stock returns are not affected by the screening process.
} 
[Insert Table 1 about here]

Columns (1)-(3) of Table 1 report the start date, end date, and length of the sample period for each country. The sample period starts when the first estimates of LTD and UTD are available, that is, after an estimation period of 12 months. In Columns (4)-(7), I provide summary statistics of the total number of firms (at specific dates in time) for each country. The United States has the highest number of unique stocks $(7,852)$, followed by the United Kingdom (5,341) and Japan (3,510). Argentina (102), Ireland (125), and Mexico (211) are the countries with the lowest number of unique stocks. ${ }^{14}$

Columns (8) and (9) display the average equal-weighted monthly return and volatility over all stocks per country. On average, the monthly return (volatility) over all countries in my sample is $1.24 \%(7.07 \%)$ per month. The country with the highest (lowest) equal-weighted monthly return in my sample period is Turkey (Portugal), with a value of 4.55\% (0.27\%) per month. Turkey (Belgium) has the highest (lowest) monthly volatility of all countries with a value of $15.62 \%$ (3.87\%) per month. ${ }^{15}$

In Column (10), I report the average equal-weighted LTD over all months and stocks in each country. The average LTD over all countries is 0.22 with Taiwan (0.38), China (0.35), and Turkey (0.33) having the highest values and Canada (0.14), Australia (0.15), and New Zealand (0.16) having the lowest values. The average equal-weighted UTD over all stocks in the sample is 0.14, with China having the highest value (0.22) and Australia having the lowest value (0.08). Finally, in Column (12), I report the average of the difference between LTD and UTD in each country. The difference is positive and statistically significant in all countries in my sample, supporting the conclusion that return dependencies generally increase more in down markets than in up markets (see, e.g., Ang and Chen 2002; Poon, Rockinger, and Tawn 2004).

I investigate the time-series behavior of aggregate LTD and aggregate UTD in Figure 2.

\footnotetext{
${ }^{14}$ The number of stocks in my study is similar to the number of stocks in Chui, Titman, and Wei (2010). In December 1996, my average sample size per country only differs by $2.84 \%$ from the sample size in Chui, Titman, and Wei's (2010) study.

${ }^{15}$ The average equal-weighted monthly return (volatility) per country is highly correlated with the average return (volatility) of the MSCI performance index for each country with a correlation coefficient of 0.74 (0.71).
} 
Aggregate LTD $\left(\operatorname{LTD}_{m, t}\right)$ is defined as the monthly cross-sectional, equal-weighted average of $\operatorname{LTD}_{i, t}$ over all stocks $i$ and countries in my sample. Analogously, I define aggregate UTD $\left(\mathrm{UTD}_{m, t}\right)$ as the monthly cross-sectional, equal-weighted average of $\mathrm{UTD}_{i, t}$ over all stocks $i$ and countries in my sample. Panel A plots the time series of $\mathrm{LTD}_{m, t}$ and $\mathrm{UTD}_{m, t}$.

\section{[Insert Figure 2 about here]}

The graph reveals that there is a slightly increasing trend in worldwide $\mathrm{LTD}_{m, t}$ in the period from 1981 to $2014 .{ }^{16}$ Occasional spikes in LTD $_{m, t}$ roughly correspond to worldwide financial crises; the highest value in $\mathrm{LTD}_{m, t}$ corresponds to early 2008 - the year of a worldwide financial crisis following the bursting of the U.S. housing bubble and the Lehman Brothers bankruptcy. Another spike in aggregate LTD occurs during 1987-the year of Black Monday - with the largest one-day percentage decline in U.S. stock market history. In contrast, when investigating the time series of aggregate UTD, there is no increasing trend in recent years. The time series of $\mathrm{LTD}_{m, t}$ and $\mathrm{UTD}_{m, t}$ are moderately correlated with a linear correlation coefficient of 0.15 .

Panel B shows the development of aggregate LTD for different geographical subsamples. The average correlation between the different aggregate LTD series is around 0.62 with the highest correlation occurring between Europe and America (0.73) and the lowest correlation between Africa/Oceania and Asia (0.31). The average aggregate LTD is 0.24 for Asia, 0.20 for Europe, 0.18 for America, and 0.15 for Africa/Oceania. ${ }^{17}$

\subsection{Returns of LTD-sorted portfolios during financial crises}

If LTD really captures the crash sensitivity of an individual stock with the market, one would expect to see an underperformance of strong LTD stocks during periods of heavy market decline. I now examine whether strong LTD stocks indeed underperform weak LTD

\footnotetext{
${ }^{16}$ I perform an augmented Dickey-Fuller test to assess the stationarity of $\mathrm{LTD}_{m, t}$. I cannot reject the null hypothesis that aggregate LTD contains a unit root with a $p$-value smaller that $10 \%$.

${ }^{17}$ I use Africa/Oceania as one geographical region because there is only one country in Africa (South Africa) and there are only two countries in Oceania (Australia and New Zealand) in my sample.
} 
stocks during periods of financial crises. Each month, I sort stocks into five quintiles based on their estimated LTD over the past 12 months. I compute average realized monthly returns of these portfolios during months in which the local market return is below its respective $5 \%$ quantile (measured over the whole market return time series for the respective country). Results for the strong LTD portfolio (portfolio 5), the weak LTD portfolio (portfolio 1), and the strong - weak LTD portfolio for the forty countries in my sample are presented in Table 2.

[Insert Table 2 about here]

As expected, strong LTD stocks strongly underperform weak LTD stocks during market crashes for each country in my sample. The differences are economically large: the monthly return of the strong LTD portfolio is between $3.01 \%$ to $16.11 \%$ lower than that of the weak LTD portfolio. On average, strong LTD stocks underperform weak LTD stocks by $-9.06 \%$ per month, if the local market return is below its respective $5 \%$ quantile. This effect is statistically significant at the $1 \%$ level with a $t$-statistic of -6.91 .

These findings show that LTD effectively captures the crash sensitivity of an individual stock. During periods of heavy market downturns, strong LTD stocks underperform while weak LTD stocks can serve as an insurance against very low market returns. Consequently, investors who are sensitive to large losses during market crashes will require a premium for holding stocks with strong LTD. Section 2 investigates the existence and magnitude of this LTD premium worldwide and for geographical subsamples.

\section{LTD and Realized Stock Returns Worldwide}

If there is a cross-sectional relationship between a stock's crash sensitivity and expected returns, one should observe patterns between average realized LTD and average realized returns. ${ }^{18}$ Hence, when documenting the impact of LTD on expected returns, I relate realized

\footnotetext{
${ }^{18}$ This assertion implicitly assumes that realized returns are, on average, a good proxy for expected returns.
} 
tail dependence coefficients to portfolio and individual security returns over the same time period. This procedure closely follows papers such as Ang, Chen, and Xing (2006) and Lewellen and Nagel (2006) and is mainly motivated by the fact that risk exposures (such as market beta) are known to be time varying (see, e.g., Fama and French 1992, and Ang and Chen 2007).

I follow the cross-sectional asset pricing studies of Kothari, Shanken, and Sloan (1995) and Ang, Chen, and Xing (2006) and work in 12-month intervals. This annual horizon offsets two concerns: First, I need a large number of daily observations to obtain reliable estimates for the LTD and UTD coefficients. Second, I can account for time-varying tail dependence by investigating relations over relatively short horizons. ${ }^{19}$ Although the estimation of risk factors is performed over a one-year horizon, I evaluate 12-month returns at a monthly frequency. The use of overlapping information in asset pricing exercises is more efficient and has greater statistical power, but also induces moving average effects at the same time. ${ }^{20}$ To adjust for these effects, t-statistics are reported using twelve Newey and West (1987) lags. The maximum sample period is from January 1981 to December 2014, with my last 12-month return period starting in January 2014.

\subsection{Portfolio sorts and factor models}

To investigate whether stocks with strong LTD earn a premium worldwide and within geographical subsamples, I first look at simple univariate portfolio sorts. In each month $t$, I sort stocks into five quintiles based on realized LTD per country over the past 12 months. ${ }^{21}$ I report the average annual realized equal-weighted local currency returns for these quintile portfolios as well as differences in average returns between quintile portfolio 5 (strong LTD) and quintile portfolio 1 (weak LTD) in panel A of Table 3.

\footnotetext{
${ }^{19}$ Figure 2 shows that aggregate LTD and UTD indeed display temporal variation over time.

${ }^{20}$ Statistical power is of high interest in my setting because some countries only have a short time series of stock market data available.

${ }^{21}$ Since LTD levels vary among countries (see Table 1), stocks are sorted into portfolios based on realized LTD within their respective country. My main results remain unchanged if I sort stocks into portfolios based on realized LTD within the worldwide sample or geographical subsamples.
} 
[Insert Table 3 about here]

Panel A indicates that stocks with strong LTD have significantly higher average returns than stocks with weak LTD on a worldwide scale. In the pooled worldwide sample, stocks in the quintile with the weakest (strongest) LTD earn an annual average return of $14.53 \%$ p.a. (21.88\% p.a). The return spread between quintile portfolios 5 and 1 is $7.35 \%$ p.a., which is statistically significant at the $1 \%$ level. Panel A also reports the relationship between LTD and average realized returns for different geographical areas. I find that stocks with strong LTD have significantly higher average returns than stocks with weak LTD in all geographical subsamples. The annual return spread between quintile portfolios 5 and 1 is large and statistically significant at the $1 \%$ level for the United States (11.54\% p.a.), the worldwide sample exluding U.S. stocks (6.45\% p.a.), America (10.92\% p.a.), Europe (7.80\% p.a.), and Africa/Oceania ( $8.32 \%$ p.a.). The smallest annual return spread of $4.56 \%$ p.a. is found in Asia which is still statistically significant at the $10 \%$ level.

Panel B displays the results of value-weighted portfolio sorts using local currency returns. ${ }^{22}$ Similar to panel A, the return spread between quintile portfolios 5 and 1 is economically large and statistically significant for the worldwide sample $(6.81 \%$ p.a. $)$ as well as for all geographical subsamples, except from Asia. The spread ranges from $9.78 \%$ p.a. in the United States to $4.92 \%$ p.a. in Asia. Hence, my results of a significant LTD premium are not driven by return patterns of very small firms.

In panel $\mathrm{C}$, I investigate whether the results are stable when performing equal-weighted portfolio sorts using USD-denominated returns. As before, the annual return spread between quintile portfolios 5 and 1 is large and statistically significant at the $1 \%$ level for the worldwide sample including U.S. stocks (6.79\% p.a.), the United States (11.54\% p.a.), the worldwide sample exluding U.S. stocks (6.01\% p.a.), America (10.83\% p.a.), Europe (7.54\% p.a.), and Africa/Oceania (8.45\% p.a.). Asia shows the smallest annual return spread of $4.67 \%$ p.a., which is statistically significant at the $10 \%$ level.

Finally, panel D reports the results of equal-weighted portfolio sorts with USD-

\footnotetext{
${ }^{22}$ Stocks in each respective quintile portfolio are weighted according to their USD market capitalization.
} 
denominated returns adjusted for the international four-factor Carhart (1997) model. ${ }^{23}$ The spreads in alphas between quintile portfolio 5 (strong LTD) and quintile portfolio 1 (weak LTD) again are statistically significant (at least at the $5 \%$ level) for the worldwide sample including U.S. stocks (5.34\% p.a.), the United States (6.40\% p.a.), the worldwide sample exluding U.S. stocks (5.00\% p.a.), America (6.10\% p.a.), Europe (5.87\% p.a.), and Africa/Oceania (5.43\% p.a.), and are usually driven by both the long and the short leg of the arbitrage portfolio. The return spread in Asia (4.01\% p.a.) is not found to be statistically significant at the $10 \%$ level. I obtain similar results when I risk adjust the returns for the international one-factor Sharpe (1964) market model or the three-factor Fama and French (1993) model (results are available upon request).

To summarize, the results of Table 3 suggest that LTD has an impact on the cross-section of average stock returns worldwide. Stocks with strong LTD contemporaneously earn high average returns in both the pooled worldwide sample and the majority of different geographical subsamples. This finding is consistent with the view that investors are crash-averse worldwide and require additional compensation for stocks that perform particularly poorly during market crashes.

\subsection{Multivariate regression analysis}

Strong LTD stocks may earn high average returns because LTD is correlated with other risk- and firm characteristics at the same time. ${ }^{24}$ Hence, I run Fama-MacBeth (1973) regressions of yearly firm returns on LTD and different risk- and firm characteristics to control for the impact of alternative explanatory variables in the period from 1981 to 2014 using

\footnotetext{
${ }^{23}$ International Fama and French (1993) factors and momentum factors are obtained from Kenneth French's Web site. Carhart (1997) alphas are estimated based on yearly portfolio and factor returns over the whole sample period using factors for the entire global region and continent/geographical areas, respectively.

${ }^{24}$ Definitions of all risk- and firm characteristics used in the asset pricing tests are contained in Panel A of Table B.1 in the Appendix. Based on the worldwide sample, LTD and UTD are positively correlated with a coefficient of 0.33 . In addition, individual LTD has strong positive correlations with beta (0.55) and size $(0.19)$ and is negatively correlated with coskewness $(-0.31)$. Individual UTD is positively correlated with beta (0.53), size (0.30), and coskewness (0.30) and negatively correlated with idiosyncratic volatility $(-0.16)$.
} 
data on the individual firm level. ${ }^{25}$ In the same way as in the portfolio sorts, I make use of overlapping information that induces moving average effects. To adjust for these effects, I report $t$-statistics using twelve Newey and West (1987) lags. Panel A of Table 4 presents the regression results for the pooled worldwide sample and geographical subsamples.

[Insert Table 4 about here]

Regressions (1)-(4) refer to the pooled worldwide sample. In regression (1), I include LTD as the only explanatory variable. It has a positive point estimate of 0.176 and is statistically significant at the $1 \%$ level. In regression (2), I add a stock's UTD coefficient. Consistent with the idea that investors are willing to hold stocks with high upside potential at a discount, I find that UTD has a significantly negative impact on returns worldwide. Regression (3) also controls for a stock's beta, size, book-to-market, and its past yearly return. My results confirm a standard set of cross-sectional return patterns: $\beta(+)$, size $(-)$, book-to-market $(+)$, and past return $(+)$ are significant variables for the cross-section of average stock returns. ${ }^{26}$ More importantly in this context, LTD remains statistically significant at the $1 \%$ level when including these additional variables. In regression (4), I expand my model by including a stock's illiquidity level (Illiq), idiosyncratic volatility (Idio Vola), and coskewness (Coskew). ${ }^{27}$ Once again, I find that the premium for LTD is statistically robust to controlling for the impact of these variables (while UTD is losing its statistical significance). LTD is also economically relevant: A one-standard-deviation increase in LTD leads to additional returns of $3.54 \%$ per annum.

\footnotetext{
${ }^{25}$ In contrast to using portfolios as test assets, this econometric procedure has the disadvantage that risk factors are estimated less precisely. However, creating portfolios lessens information by reducing the dispersion of risk factors which leads to larger standard errors. Ang, Liu, and Schwarz (2010) show that the smaller standard errors of risk factor estimates from creating portfolios do not necessarily lead to smaller standard errors of cross-sectional coefficient estimates.

${ }^{26}$ Firm size (book-to-market) is shown to have a negative (positive) impact on expected returns in the United States (e.g., Fama and French 1992; Fama and French 1993) as well as on international stock markets (e.g., Fama and French 1998; Griffin 2002). Past winner (loser) stocks over the previous 3 to 12 months are found to continue to perform well (poorly) over the subsequent 3 to 12 months in the United States (e.g., Jegadeesh and Titman 1993) and throughout the world (e.g. Rouwenhorst 1998; Griffin, Ji, and Martin 2003; Asness, Moskowitz, and Pedersen 2013).

${ }^{27}$ In line with Amihud (2002) and Harvey and Siddique (2000), I document that Illiq (Coskew) shows a positive (negative) impact on the cross-section of average stock returns, respectively. I do not find a statistically significant impact of Idio Vola, consistent with the results of Bali and Cakici (2008).
} 
Regressions (5)-(9) report the results of regression (4) for different geographical subsamples. The LTD point estimate ranges from 0.415 for the United States to 0.136 for Asia, implying that a one-standard-deviation increase in LTD leads to additional returns of $4.55 \%$ p.a. in the United States (1.88\% p.a. in Asia). The economic impact of UTD for different geographical subsamples is considerably weaker and not statistically significant. ${ }^{28}$

In panel B of Table 4, I provide different robustness tests for the relationship between crash sensitivity and average stock returns. I run Fama-MacBeth (1973) regressions of yearly firm returns on LTD and different risk- and firm characteristics as in regression (4) of panel A, but only report the coefficient estimates for the impact of LTD. All other explanatory variables are included in the regressions, but their coefficient estimates are suppressed.

As a first stability check, I estimate LTD coefficients with different market returns. Instead of computing the market return as the value-weighted average of all domestic stock returns in the country (baseline specification), I use (1) a market return computed as the equal-weighted average of all domestic stock returns in the country, (2) the local MSCI price index return, and (3) the world MSCI price index return. I find that LTD has a statistically significant impact on average stock returns in the pooled worldwide sample and in all geographical subsamples when computed as in (1)-(3). Intuitively, my results indicate a weaker economic relationship when LTD is estimated with the world MSCI price index return. This finding is consistent with results from Griffin (2002), who documents that country-specific factor models better capture temporal variation in stock returns than do global factor models.

Second, instead of selecting the appropriate parametric copula based on estimated loglikelihood values for each country, I ex ante randomly select copulas (1)-(B)-(I), (2)-(B)-(I), (3)-(B)-(IV), and (4)-(D)-(IV) from Table A.1 in the LTD estimation process. Overall, the impact of LTD is significant and stable across different copulas.

Finally, I investigate the impact of a related bivariate downside risk measure (instead of

\footnotetext{
${ }^{28}$ In specifications (4), (5), (7), and (10), the coefficient estimate on past yearly return, i.e., the momentum effect, is positive but statistically insignificant at the $10 \%$ level. I attribute this result (which is, e.g., in contrast to the findings of Asness, Moskowitz, and Pedersen (2013)) to the fact that I evaluate 12-month returns in the asset pricing tests. When I use one-month ahead returns as the dependent variable (as in Panel $\mathrm{E}$ of Tables 8 and 9), positive and statistically significant estimates for momentum in all specifications except from Asia are obtained.
} 
LTD) on the cross-section of average stock returns. I select the downside beta $\left(\beta^{-}\right)$proposed by Ang, Chen, and Xing (2006) and defined as market beta conditional on daily market returns being below the average market return estimated over the past 12 months (see panel A of Table B.1 in the Appendix). I find that $\beta^{-}$has a significant relationship with average stock returns in the pooled worldwide sample and in all geographical subsamples except from Asia. However, the impact of $\beta^{-}$is statistically and economically weaker in comparison to the impact of LTD: A one-standard-deviation increase in $\beta^{-}$leads to additional returns of $1.81 \%$ p.a. (in comparison to $3.54 \%$ p.a. for a one-standard-deviation increase in LTD) based on results of the pooled worldwide sample.

In summary, I find convincing evidence that LTD is an important determinant to explain the cross-section of average stock return worldwide as well as for most geographical subsamples. The impact of LTD is statistically and economically important even when controlling for a wide array of different risk factors and firm characteristics.

\subsection{Time-varying crash aversion of investors}

Investors tend to overstate the fear of a future market crash when they can remember the occurrence of a black swan event (see Gennaioli, Shleifer, and Vishny 2015). Consistent with this notion, Chabi-Yo, Ruenzi, and Weigert (2015) find that the premium for a stock's LTD in the United States is more than twice as high following the years after an extreme market downturn than in the remaining years. ${ }^{29}$

Hence, to investigate whether the occurrence of a financial crisis also increases the LTD premium in different stock markets around the world, I split my data set into two subsamples: for each country I define the "post-market crash" subsample containing the three years after an extreme market downturn has occurred and the "remaining years" subsample. I define "extreme market downturns" as the three worst return months for each country in my sample. Table 5 repeats regression (4) from Table 4 for both the "post-market crash" subsample, as

\footnotetext{
${ }^{29}$ In a similar vein, it is sometimes argued in the empirical option literature that investors became crasho-phobic after the experience of the 1987 crash (Rubinstein 1994; Bates 2000).
} 
well as for the "remaining years" subsample worldwide and across different geographical regions. I only report the coefficient estimates for the impact of LTD. All other explanatory variables are included in the regressions, but their coefficient estimates are suppressed.

[Insert Table 5 about here]

My results indicate that the impact of LTD on returns is indeed much stronger in years following an extreme market downturn. Based on results of the worldwide sample, the impact of LTD on returns is almost twice as high in the "post-market crash" subsample than for the remaining years. I obtain similar results for the different geographical areas. Overall, this result implies that investors require a high premium for taking a stock's crash sensitivity, in particular when a market crash has occurred in the recent past.

\subsection{Country-specific LTD premiums}

In this section, I present the results of country-specific LTD premiums. Table 6 reports the results of equal-weighted univariate portfolio sorts with local currency returns (as in panel A of Table 3) and Fama and MacBeth (1973) regressions of yearly firm returns on LTD and different risk- and firm characteristics (as in panel A of Table 4) for each of the forty countries in my sample. I report the average yearly return for the top (bottom) quintile LTD portfolio, the return difference for the strong - weak LTD portfolio, and the coefficient estimate for LTD from the same regression (4) setup found in panel A of Table $4 .{ }^{30}$

[Insert Table 6 about here]

Columns (1)-(3) display the results of the country-specific portfolio sorts. I find that in all but five countries, the return spread of the strong - weak LTD portfolio is positive. The difference is statistically significant at the $10 \%$ level (5\% level, $1 \%$ level) in $19(16,6)$ of the 40 countries. The countries with the highest return spread are the United States (11.54\%

\footnotetext{
${ }^{30}$ Again, I only report the coefficient estimates for the impact of LTD and truncate all control variable coefficients.
} 
p.a.), Australia (10.63\% p.a.), and the United Kingdom (9.92\% p.a.). The lowest spreads are found in China (-2.57\% p.a.), South Korea (-2.27\% p.a.), and Taiwan (-1.61\% p.a.).

In Column (4), I display the coefficient estimate for the county-specific LTD coefficient in the Fama and MacBeth (1973) regressions. Except for six countries, the LTD coefficient estimate is positive. Furthermore, the LTD coefficient is statistically significant at the $10 \%$ level $(5 \%$ level, $1 \%$ level $)$ in $22(18,13)$ of the 40 countries. The countries with the highest LTD coefficient are Argentina (0.524), the Netherlands (0.501), and Canada (0.461). The countries with the lowest LTD coefficients are China (-0.201), Brazil (-0.145), and the Philippines (-0.121).

\subsection{Determinants of the LTD premium}

The results in Sections 2.1 and 2.2 reveal that LTD has an impact on the cross-section of average stock returns worldwide. However, the risk premium for a stock's LTD drastically varies across countries (Section 2.4). Hence, I next turn to the question of which factors drive the differences in the magnitude of the country-specific LTD premiums. To do so, I regress the yearly country-specific LTD premiums on potential determinants:

$$
\operatorname{LTD~Premium}_{i, y}=\alpha+\beta_{1} F_{i}+\beta_{2} T_{i, y}+\epsilon_{i, y}
$$

where LTD Premium $i, y$ is the return difference between top quintile LTD stocks and weak quintile LTD stocks in country $i$ in year $y, F_{i}$ is a vector of explanatory variables in country $i$ that are constant over time, $T_{i, y}$ is a vector of explanatory variables in country $i$ that are updated annually, and $\epsilon_{i, y}$ is an error term. In this section, I use nonoverlapping return data to compute the LTD premium, as well as a pooled ordinary least squares (OLS) regression framework with yearly time dummies and clustered standard errors by country, to estimate Equation (5). All explanatory variables are defined in panel B of Table B.1 in the Appendix. 
2.5.1 Stock market characteristics. In this paper, I capture a stock's crash sensitivity based on its LTD with the market. LTD, as defined in (1), is the probability that a stock return is in the extreme lower tail of its distribution conditional on the market return also being in the extreme lower tail of its distribution. LTD tells us how likely it is that a stock realizes its worst return exactly at the time at which the market realizes its worst return; however, it does not take into account how bad the worst return realization of the stock really is. The premium of LTD should be higher in countries in which one can expect the worst return realization of a stock to be particularly low. Particular low return realizations should occur in countries with high stock market volatility (Vola), low (negative) market skewness (Skew), and high market kurtosis (Kurt). I investigate the impact of these (annually updated) variables in regression (1) of Table $7 .{ }^{31}$

[Insert Table 7 about here]

In line with predictions, the empirical results reveal that the coefficient estimates of Vola and Kurt are positive; however, the effects are not statistically significant. I find a strongly significant negative relationship between market skewness and the magnitude of the LTD premium. This result is intuitive: if the market return is negatively skewed, the left tail of return observations is fatter than the right (positive) tail and extreme stock market downturns are particularly pronounced. To compensate for these severe market crashes, investors require a high compensation for a stock's LTD.

2.5.2 Investor characteristics. Generally, the premium for a stock's LTD should be high (low) in those countries in which local stock market investors exhibit a high (low) degree of aversion against extreme market crashes. Recent literature documents that an important factor determining risk preferences of individuals in the cross-section (and particularly across countries) is wealth, for example, Statman (2008), Rieger, Wang, and Hens (2015) and Paravisini, Rappoport, and Ravina (2015) find that wealthier individuals are more risk

\footnotetext{
${ }^{31}$ I also control for country $i$ 's stock market illiquidity (Market illiq) in year $y$ (computed as the annual, equal-weighted average of Illiq) and stock market turnover (Turnover) in regression (1).
} 
averse. To the contrary, Guiso and Paiella (2008) and Tanaka, Camerer, and Nguyen (2010) document a negative association between wealth and risk aversion parameters. Hence, to investigate the relationship between crash aversion and wealth of investors, I regress country $i$ 's LTD premium in year $y$ on country $i$ 's gross national income per capita (GNI, as a proxy for investor wealth) in year $y$. In addition, I also investigate the impact of investor characteristics that are possibly correlated with crash aversion and vary across countries: a country's stock market participation rate (Participation), home bias of investors (Home bias), and a country's inhabitants' average length of schooling (Schooling). Regression (2) of Table 7 reports the results.

I find that GNI is the only variable (among the different investor characteristics) significantly related to the magnitude of the LTD premium and carries a positive coefficient estimate of 0.231 . Hence, my results support the notion that individuals from wealthier countries are more crash averse.

2.5.3 Cultural attitudes. Research in psychology indicates a strong association between cultural background and individuals' attidudes towards financial risk taking. Weber and Hsee (1998) and Hsee and Weber (1999) document that people in individualistic (IND) countries tend to be more risk averse in financial decisions than people in collectivistic countries. ${ }^{32}$ In addition, societies with a high degree of uncertainty avoidance (UAI) feel uncomfortable with uncertainty and ambiguity. ${ }^{33}$ As an example, Frijns et al. (2013) document that CEOs of firms located in countries with high UAI scores require higher premiums on takeovers and engage less in cross-border takeovers. I investigate whether cultural differences in societies are correlated with the LTD premium in specification (3) of Table 7. To do so, I regress country $i$ 's LTD premium in year $y$ on the six cultural dimensions of Hofstede (2001)'s model: indi-

\footnotetext{
${ }^{32}$ Countries with a score on the high side of the IND dimension represent a society where people look after themselves and their immediate family only. In contrast, countries with a score on the low side of this dimension, i.e., collectivistic countries, represent a society where people belong to in-groups that look after them in exchange for loyalty.

${ }^{33}$ Countries exhibiting high UAI maintain rigid codes of belief and behaviour and are intolerant of unorthodox behaviour and ideas. To the contrary, low UAI societies maintain a more relaxed attitude in which practice counts more than principles.
} 
vidualism (IND), uncertainty avoidance (UAI), power distance (PDI), masculinity (MAS), long-term orientation (LTO) and indulgence (INDUL).

As conjectured, I find a significant positive relationship between IND and the magnitude of the LTD premium. Following Weber and Hsee (1998) and Hsee and Weber (1999), one can explain this finding in terms of a "cushion hypothesis": in collectivistic countries (e.g., China) a tightly knit social network serves as a cushion in the case of large financial lossesconsequently, investors only require a marginal compensation for a stock's LTD. In contrast, there is a substantial LTD premium in individualistic countries (e.g., United States), where investors personally have to insure against the risk of large financial losses. Except from IND, I do not find a significant association between any of the cultural variables and the LTD premium.

Finally, in specification (4), I regress the LTD premium on variables that show statistical significance in regressions (1)-(3) of Table 7. Hence, country $i$ 's LTD premium in year $y$ is regressed on market skewness (Skew, annually updated), gross national income per capita (GNI, annually updated), and individualism (IND, static). When pooling these variables in a joint model, I still find that Skew, GNI, and IND remain to have a statistically significant impact on the magnitude of the LTD premium. My empirical results indicate that (as hypothesized) the premium for a stock's LTD is high in countries in which stock market crashes are particularly severe (impact of Skew) and local stock market investors are likely to exhibit a high degree of crash aversion (impact of GNI and IND).

\section{$3 \quad$ LTD and Future Stock Returns Worldwide}

So far, I have documented that there exists a strong positive relationship between stocks with strong LTD and returns for holding such stocks over the same period. My next step is to examine whether LTD is persistent over time and whether it also predicts cross-sectional differences in future returns.

In untabulated results, I find evidence of predictive power of current LTD on future LTD. 
Regressing future LTD (LTD at month $t+12$ ) on current LTD (LTD at month $t$ ) in a univariate model delivers a coefficient estimate of 0.351 with a $t$-statistic of 10.43 and a $R$ squared of $0.276 .^{34}$ This pattern indicates that there exists predictability in LTD; however, although highly statistically significant, the coefficient estimate is far from one and one should expect that using only current LTD to predict future returns may be difficult.

I now investigate whether stocks simply sorted on current LTD provide enough variation in future LTD to provide large spreads in future returns. To do so, in each month $t$, I sort stocks into five portfolios based on realized LTD per country over the past 12 months. I examine future returns of these portfolios over the following month $t+1$. Average future monthly returns in local currency for the quintile portfolios 5 , as well as differences in returns between these both portfolios are reported in panel A of Table 8.

[Insert Table 8 about here]

I find an increasing relationship between LTD and future returns on a worldwide scale. Column 1 shows that stocks in the quintile with the weakest (strongest) LTD earn an average future monthly return of $0.91 \%(1.20 \%)$. The spread in future returns between quintile portfolios 5 and 1 is $0.29 \%$ per month, but is not wide enough to be statistically significant at the $10 \%$ level. In a similar manner, the average future monthly return spread due to LTD is positive but statistically insignificant for the worldwide sample, excluding U.S. stocks (0.27\%), Europe (0.29\%), Africa/Oceania (0.26\%), and Asia (0.14\%). In contrast to the majority of different regions in my sample, I find a large and statistically significant spread in future returns for the United States (0.45\% per month) and America (0.43\% per month).

To check whether the results are similar when applying different examination methods, I report the results of value-weighted predictive sorts in panel $\mathrm{B}$, equal-weighted predictive sorts with USD-denominated returns in panel C, equal-weighted predictive sorts adjusted for the international international four-factor Carhart (1997) model in panel D, and the results

\footnotetext{
${ }^{34}$ The predictive power of current LTD on future LTD is also stable across the geographical subsamples. The regression of future LTD on current LTD yields a significant estimate of 0.304 for the United States, 0.372 for the worldwide sample (excl. the United States), 0.311 for America, 0.397 for Europe, 0.408 for Africa/Oceania, and 0.425 for Asia.
} 
of Fama and MacBeth (1973) regressions of future monthly returns on LTD and other riskand firm characteristics in panel E. As before, I document a positive worldwide impact of LTD on average future monthly returns in all four additional panels. However, the influence is not statistically significant at the $10 \%$ level, respectively.

\subsection{LTD and future stock returns worldwide: A refinement}

Finally, I consider a possible refinement of predicting future LTD using current LTD. Following Ang, Chen, and Xing (2006), I concentrate on the confounding influence of a stock's volatility in the prediction exercise. For the strong contemporaneous pattern between LTD and average stock returns to be exploited in an investable portfolio strategy, I must accurately forecast future LTD. When return volatility is high, the LTD estimates are likely to contain substantial measurement error. Hence, high volatility leads the persistence of LTD to be lower, and future LTD coefficients to be less predictable.

I find strong evidence of an important confounding impact of a stock's volatility when predicting future LTD using current LTD. A stock is classified as highly volatile at month $t$ if its historical one-year standard deviation is in the top decile among all stocks in the respective country. Regressing future LTD (LTD at month $t+12$ ) on current LTD (LTD at month $t$ ) in a univariate model delivers a coefficient estimate of 0.232 for high volatility stocks as compared to 0.405 for the remaining stocks in the worldwide sample (including the United States). I obtain similar coefficient estimate differences for the respective geographical subsamples: the LTD estimate for high volatility stocks in the United States (the worldwide sample, excluding U.S. stocks, America, Europe, Africa, Asia) is 0.202 (0.248, 0.218, 0.256, $0.265,0.269)$, and it is $0.323(0.402,0.321,0.401,0.435,0.421)$ for the remaining stocks. Hence, persistence in LTD is more than $70 \%$ higher for a typical stock as compared to a high volatility stock.

With this information in hand, I repeat the asset pricing tests of Table 8 when excluding stocks with high volatility. Fortunately, the proportion of high volatility stocks in the market consists of less than $5 \%$ in terms of the average country's market capitalization. Panel A of 
Table 9 reports the results of equal-weighted predictive sorts with local currency returns.

[Insert Table 9 about here]

Column 1 shows that, when excluding stocks with high volatility, the future return spread due to LTD considerably widens. Worldwide, stocks in the strongest (weakest) LTD quintile earn average future monthly returns of $0.87 \%(1.27 \%)$. Thus, a refined trading strategy of investing in strong LTD stocks and shorting weak LTD stocks delivers an economically significant future return of $0.40 \%$ per month, which is statistically significant at the $5 \%$ level. The spread translates into an annualized return premium of $4.80 \%$ p.a. I also find that strong LTD stocks have significantly higher future returns than weak LTD stocks in all geographical subsamples, except from Asia.

To examine whether the refined results are stable, I also report the results of value-weighted predictive sorts in panel B, equal-weighted predictive sorts with USD-denominated returns in panel $\mathrm{C}$, equal-weighted predictive sorts adjusted for the international international fourfactor Carhart (1997) model in panel D, and the results of Fama and MacBeth (1973) regressions of future monthly returns on LTD and other risk- and firm characteristics in panel E of Table 8. I find that the future return spreads due to LTD (in panels B-D), as well as the coefficient estimate for LTD (in panel E) are economically large and statistically significant for all geographical subsamples, except from Asia.

Overall, these findings suggest that it is possible to create a profitable trading strategy based on past LTD when excluding the small proportion of stocks that exhibit high volatility. Notice that these results do not take into account any forms of trading costs and other limits of arbitrage.

\section{Conclusion}

This paper examines the impact of a stock's crash sensitivity on the cross-section of expected stock returns around the world. If investors derive disproportionately large disutility 
from large losses, they should require a risk premium for holding crash-sensitive stocks. Investigating stock market data from forty countries, I find that crash sensitivity (as measured by a stock return's lower tail dependence (LTD) with the market return) has a strong positive impact on the cross-section of average stock returns. Stocks with strong LTD earn significantly higher returns than stocks with weak LTD not only worldwide, but also in geographically subsamples and for most individual countries. Controlling for a wide array of different systematic risk- and firm characteristics, an increase of one standard deviation in LTD is associated with an average worldwide return premium of more than $3 \%$ p.a.

Even though the positive impact of LTD on stock returns is found both in the pooled worldwide sample and in geographical subsamples, there exist large country-wide differences in the magnitude of this risk premium. I document that the magnitude of the LTD premium is high in countries characterized by negative market skewness, high income per capita, and high individualism. These findings are in line with the notion that the premium for a stock's LTD is high in countries in which stock market crashes are particularly severe and where local stock market investors are likely to exhibit a high degree of crash aversion.

Finally, I provide evidence that current LTD reliably forecasts future LTD, except for stocks that are extremely volatile. Hence, LTD can be used to predict cross-sectional differences in future returns for the majority of stocks worldwide. The future spread due to LTD (when excluding stocks with very high volatility from the sample) is economically large and cannot be explained by different systematic risk- and firm characteristics. 


\section{A Appendix: Estimating LTD}

Technical details regarding the copula estimation and selection procedure and the calculation of the respective tail dependence coefficients are provided in Appendix A. The estimation procedure follows the approach of Chabi-Yo, Ruenzi, and Weigert (2015).

\section{A.1 The Estimation Procedure}

Coefficients of tail dependence have analytical solutions for several parametric copulas (see Table A.1), but these basic copulas do not allow us to model upper and lower tail dependence simultaneously. However, Tawn (1988) proves that every convex combination of existing copula functions is again a copula. Thus, if $C_{1}\left(u_{1}, u_{2}\right), C_{2}\left(u_{1}, u_{2}\right), \ldots, C_{n}\left(u_{1}, u_{2}\right)$ are bivariate copula functions, then

$$
C\left(u_{1}, u_{2}\right)=w_{1} \cdot C_{1}\left(u_{1}, u_{2}\right)+w_{2} \cdot C_{2}\left(u_{1}, u_{2}\right)+\ldots+w_{n} \cdot C_{n}\left(u_{1}, u_{2}\right)
$$

is again a copula for $w_{i} \geq 0$ and $\sum_{i=1}^{n} w_{i}=1$.

For the computation of tail dependence coefficients, I consider all 64 possible convex combinations of the basic copulas from Table A.1, each of which consists of one copula that allows for asymptotic dependence in the lower tail, $C_{\mathrm{LTD}}$, one copula that is asymptotically independent, $C_{\mathrm{NTD}}$, and one copula that allows for asymptotic dependence in the upper tail, $C_{\mathrm{UTD}}$ :

$$
\begin{aligned}
& C\left(u_{1}, u_{2}, \Theta\right)=w_{1} \cdot C_{\mathrm{LTD}}\left(u_{1}, u_{2} ; \theta_{1}\right) \\
& \quad+w_{2} \cdot C_{\mathrm{NTD}}\left(u_{1}, u_{2} ; \theta_{2}\right)+\left(1-w_{1}-w_{2}\right) \cdot C_{\mathrm{UTD}}\left(u_{1}, u_{2} ; \theta_{3}\right),
\end{aligned}
$$

where $\Theta$ denotes the set of the basic copula parameters $\theta_{i}, i=1,2,3$ and the convex weights $w_{1}$ and $w_{2}$.

My estimation approach can be divided into two different sample periods: the presample period (the first year of available daily data for each country) and the main sample period (all daily data after the first year).

\section{A.1.1 Estimation in the presample period}

The presample period is used to determine the copula convex combination that best fits the distribution between an individual stock return $r_{i}$ and the market return $r_{m}$ for all stocks $i$ in a country. First, based on daily returns, a set of copula parameters $\Theta_{j}$ for $j=1, \ldots, 64$ different copulas $C_{j}\left(\cdot, \cdot ; \Theta_{j}\right)$ is estimated between an individual daily stock return $r_{i}$ and the 
daily market return $r_{m}$ for each stock $i$ based on a 12-month horizon. Each of these convex combinations requires the estimation of five parameters: one parameter $\theta_{i}(i=1,2,3)$ for each of the three basic copulas and two parameters for the weights $w_{1}$ and $w_{2}$. The copula parameters $\Theta_{j}$ are estimated via the canonical maximum likelihood procedure of Genest, Ghoudi, and Rivest (1995). The details of this step are described in Section A.2.

Second, for each stock $i$, I compare the estimated log-likelihood values of all 64 copulas $C_{j}$ and select the parametric copula $C_{j}^{*}\left(\cdot, \cdot ; \Theta^{*}\right)$ that has the highest log-likelihood value. As best-fitting copula for the bivariate distribution between a stock's return and market return for the respective country, I select copula $C^{*}\left(\cdot, \cdot ; \Theta^{*}\right)$, which is the copula selected most frequently within the sample of all stocks. The result of this step is summarized in Table A.2 where the highest absolute and percentage frequency copula combination is presented for each country in the sample.

\section{A.1.2 Estimation in the main sample period}

In the main sample period, I use the best-fitting copula $C^{*}\left(\cdot, \cdot ; \Theta^{*}\right)$ in the respective country for the estimation of the copula parameters $\Theta_{i, t}^{*}$ between an individual daily stock return $r_{i, t}$ and the daily market return $r_{m, t}$ for each stock $i$ and month $t$ based on a rolling 12month horizon. Again, the copula parameters $\Theta_{i, t}^{*}$ are estimated via the canonical maximum likelihood procedure of Genest, Ghoudi, and Rivest (1995) (see Section A.2).

Finally, the LTD coefficients (and UTD coefficents) implied by the estimated parameters $\Theta_{i, t}^{*}$ of the selected copula $C^{*}\left(\cdot, \cdot ; \Theta^{*}\right)$ are computed. The computation of LTD is straightforward if the copula in question has a closed form, which holds for all copulas in the study. Column (3) of Table A.1 displays the closed-form solutions to determine LTD for the respective copula. ${ }^{35}$ The LTD coefficient of the convex combination is calculated as the weighted sum of the LTD coefficients from the individual copulas, i.e., $\operatorname{LTD}^{*}=w_{1}^{*} \cdot \operatorname{LTD}\left(\theta_{1}^{*}\right) \cdot{ }^{36}$ Since this procedure is repeated for each stock and month, the end result is a panel of $\mathrm{LTD}_{i, t}$ (and $\left.\mathrm{UTD}_{i, t}\right)$ coefficients at the stock-month level.

\section{A.2 Estimation of the Copula Parameters}

The estimation of the set of copula parameters $\Theta$ for a copula $C(\cdot, \cdot ; \Theta)$ is performed as follows (see also Genest, Ghoudi, and Rivest 1995; Chabi-Yo, Ruenzi, Weigert 2015):

Let $\left\{r_{i, k}, r_{m, k}\right\}_{k=1}^{n}$ be a random sample from the bivariate distribution

\footnotetext{
${ }^{35}$ Column (4) of Table A.1 displays the closed-form solutions to determine UTD for the respective copula.

${ }^{36}$ The UTD coefficient of the convex combination is calculated as $\mathrm{UTD}^{*}=\left(1-w_{1}^{*}-w_{2}^{*}\right) \cdot \operatorname{UTD}\left(\theta_{3}^{*}\right)$.
} 


$$
F\left(r_{i}, r_{m}\right)=C\left(F_{i}\left(r_{i}\right), F_{m}\left(r_{m}\right)\right)
$$

between an individual stock return $r_{i}$ and the market return $r_{m}$, where $n$ denotes the number of daily return observations in a 12 -month period. I estimate the marginal distributions $F_{i}$ and $F_{m}$ of an individual stock return $r_{i}$ and the market return $r_{m}$ nonparametrically by their scaled empirical distribution functions

$$
\widehat{F}_{i}(x)=\frac{1}{n+1} \sum_{k=1}^{n} \mathbb{1}_{r_{i, k} \leq x} \quad \text { and } \quad \widehat{F}_{m}(x)=\frac{1}{n+1} \sum_{k=1}^{n} \mathbb{1}_{r_{m, k} \leq x} .
$$

The estimation of $F_{i}$ and $F_{m}$ by their empirical counterparts avoids any incorrect specification of marginal distributions. The set of copula parameters $\Theta$ are estimated via the maximum likelihood estimator

$$
\widehat{\Theta}=\operatorname{argmax}_{\Theta} L(\Theta) \quad \text { with } \quad L(\Theta)=\sum_{k=1}^{n} \log \left(c\left(\widehat{F}_{i, r_{i, k}}, \widehat{F}_{m, r_{m, k}} ; \Theta\right)\right),
$$

where $L(\Theta)$ denotes the log-likelihood function and $c(\cdot, \cdot ; \Theta)$ the copula densitiy. Assuming that $\left\{r_{i, k}, r_{m, k}\right\}_{k=1}^{n}$ is an i.i.d. random sample, $\widehat{\Theta}$ is shown to be a consistent and asymptotic normal estimate of the set of copula parameters $\Theta$ under standard regularity conditions. ${ }^{37}$

\footnotetext{
${ }^{37}$ Daily return data often violates the assumption of an i.i.d. random sample. Hence, an alternative approach to the problem of non-i.i.d. data due to serial correlation in the first and the second moment of the time series would be to specify an ARMA-GARCH model for the univariate processes and analyze the dependence structure of the residuals. I decide not to filter the data, since filtering will also change the data's dependence structure (see Jalal and Rockinger 2008).
} 


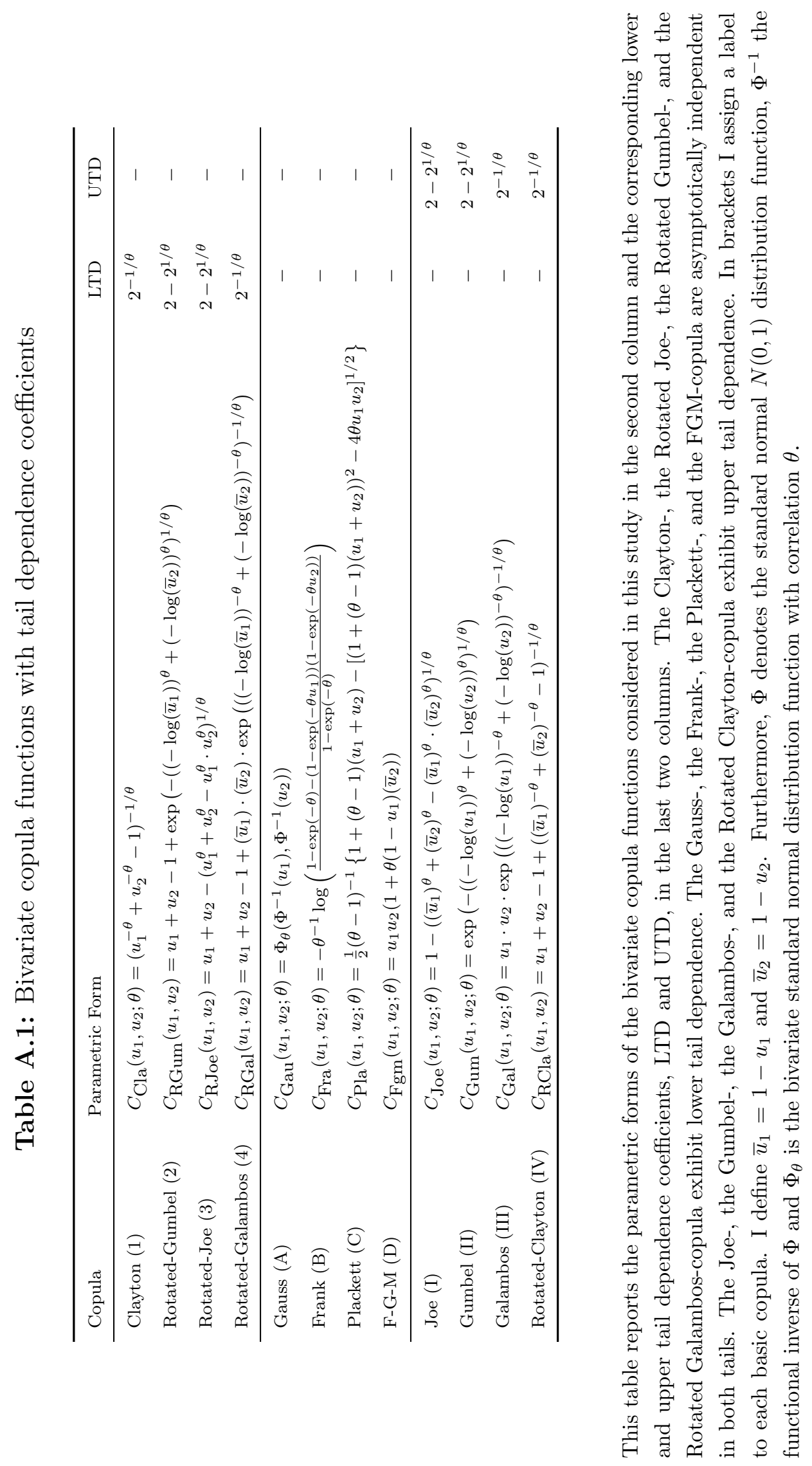


Table A.2: Copula selection

\begin{tabular}{|c|c|c|c|c|}
\hline Country & Copula & Name & Freq & $\%$ \\
\hline Argentina & 3-C-II & Rotated Joe - Plackett - Gumbel & 4 & 8.33 \\
\hline Australia & 2-D-I & Rotated-Gumbel - FGM - Joe & 8 & 5.37 \\
\hline Austria & 1-A-II & Clayton - Gauss - Gumbel & 4 & 9.52 \\
\hline Belgium & 3-D-I & Rotated-Joe - FGM - Joe & 5 & 9.62 \\
\hline Brazil & 2-B-III & Rotated-Gumbel - Frank - Galambos & 3 & 9.68 \\
\hline Canada & $2-\mathrm{D}-\mathrm{I}$ & Rotated-Gumbel - FGM - Joe & 16 & 5.16 \\
\hline Chile & 1-A-II & Clayton - Gauss - Gumbel & 4 & 6.78 \\
\hline China & 3-D-II & Rotated-Joe - FGM - Gumbel & 6 & 4.72 \\
\hline Denmark & 3-D-I & Rotated-Joe - FGM - Joe & 7 & 8.33 \\
\hline Finland & 1-D-I & Clayton - FGM - Joe & 3 & 8.82 \\
\hline France & $1-\mathrm{D}-\mathrm{I}$ & Clayton - FGM - Joe & 10 & 7.09 \\
\hline Germany & 1-A-II & Clayton - Gauss - Gumbel & 9 & 6.34 \\
\hline Greece & 1-B-II & Clayton - Frank - Gumbel & 6 & 13.04 \\
\hline Hong Kong & $2-\mathrm{D}-\mathrm{I}$ & Rotated-Gumbel - FGM - Joe & 7 & 11.29 \\
\hline India & $4-\mathrm{A}-\mathrm{I}$ & Rotated-Galambos - Gauss - Joe & 16 & 5.10 \\
\hline Indonesia & 2-B-III & Rotated-Gumbel - Frank - Galambos & 5 & 7.35 \\
\hline Ireland & 4-D-IV & Rotated-Galambos - FGM - Rotated-Clayton & 2 & 4.65 \\
\hline Israel & 1-A-II & Clayton - Gauss - Gumbel & 20 & 7.33 \\
\hline Italy & 4-B-II & Rotated-Galambos - Frank - Gumbel & 7 & 8.54 \\
\hline Japan & $4-\mathrm{D}-\mathrm{I}$ & Rotated-Galambos - FGM - Joe & 30 & 3.78 \\
\hline Malaysia & $4-\mathrm{A}-\mathrm{I}$ & Rotated-Galambos - Gauss - Joe & 10 & 5.32 \\
\hline Mexico & 3-C-II & Rotated-Joe - Plackett - Gumbel & 2 & 4.08 \\
\hline Netherlands & $4-\mathrm{D}-\mathrm{I}$ & Rotated-Galambos - FGM - Joe & 9 & 5.81 \\
\hline New Zealand & $3-\mathrm{C}-\mathrm{I}$ & Rotated-Joe - Plackett - Joe & 3 & 6.25 \\
\hline Norway & $4-\mathrm{D}-\mathrm{I}$ & Rotated-Galambos - FGM - Joe & 3 & 8.57 \\
\hline Pakistan & 1-B-II & Clayton - Frank - Gumbel & 7 & 7.45 \\
\hline Philippines & 4-B-II & Rotated-Galambos - Frank - Gumbel & 3 & 7.69 \\
\hline Poland & 1-A-II & Clayton - Gauss - Gumbel & 5 & 9.09 \\
\hline Portugal & 2-D-III & Rotated-Gumbel - FGM - Galambos & 8 & 11.59 \\
\hline Singapore & $4-\mathrm{D}-\mathrm{I}$ & Rotated-Galambos - FGM - Joe & 9 & 10.11 \\
\hline South Africa & 3-D-I & Rotated-Joe - FGM - Joe & 7 & 9.21 \\
\hline South Korea & 2-D-III & Rotated-Gumbel - FGM - Galambos & 15 & 6.58 \\
\hline Spain & 1-A-II & Clayton - Gauss - Gumbel & 4 & 7.14 \\
\hline Sweden & 2-C-IV & Rotated-Gumbel - Plackett - Rotated-Clayton & 7 & 10.94 \\
\hline Switzerland & 2-C-IV & Rotated-Gumbel - Plackett - Rotated-Clayton & 11 & 13.92 \\
\hline Taiwan & $4-\mathrm{D}-\mathrm{I}$ & Rotated-Galambos - FGM - Joe & 23 & 15.97 \\
\hline Thailand & $3-\mathrm{C}-\mathrm{I}$ & Rotated-Joe - Plackett - Joe & 8 & 8.89 \\
\hline Turkey & 1-B-II & Clayton - Frank - Gumbel & 4 & 8.89 \\
\hline United Kingdom & $3-\mathrm{C}-\mathrm{I}$ & Rotated-Joe - Plackett - Joe & 93 & 5.98 \\
\hline USA & 3-D-I & Rotated-Joe - FGM - Joe & 69 & 3.36 \\
\hline
\end{tabular}

This table reports the absolute and percentage frequency of the selected parametric copula combinations in the presample period (first year of available data) for each country. Based on daily return data, I fit all sixty-four possible convex copula combinations to the distribution between an individual stock return $r_{i}$ and the market return $r_{m}$ for all stocks $i$ in a country. For each country, I select the respective copula combination $C^{*}\left(\cdot, \cdot ; \Theta^{*}\right)$, which is chosen most frequently based on the estimated log-likelihood value. Labels of the respective copula combinations are based on the basic copula subsets from Table A.1. 


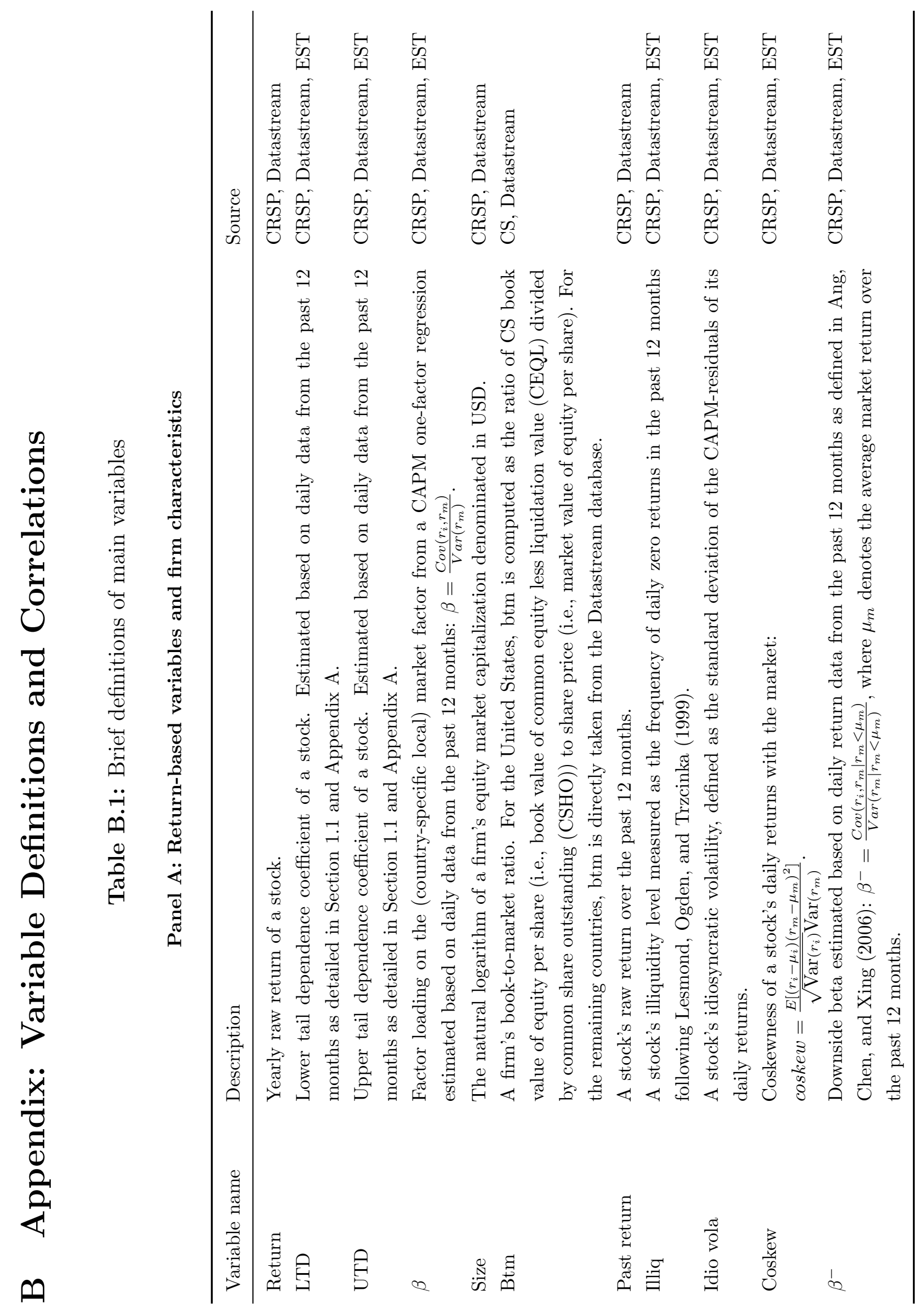




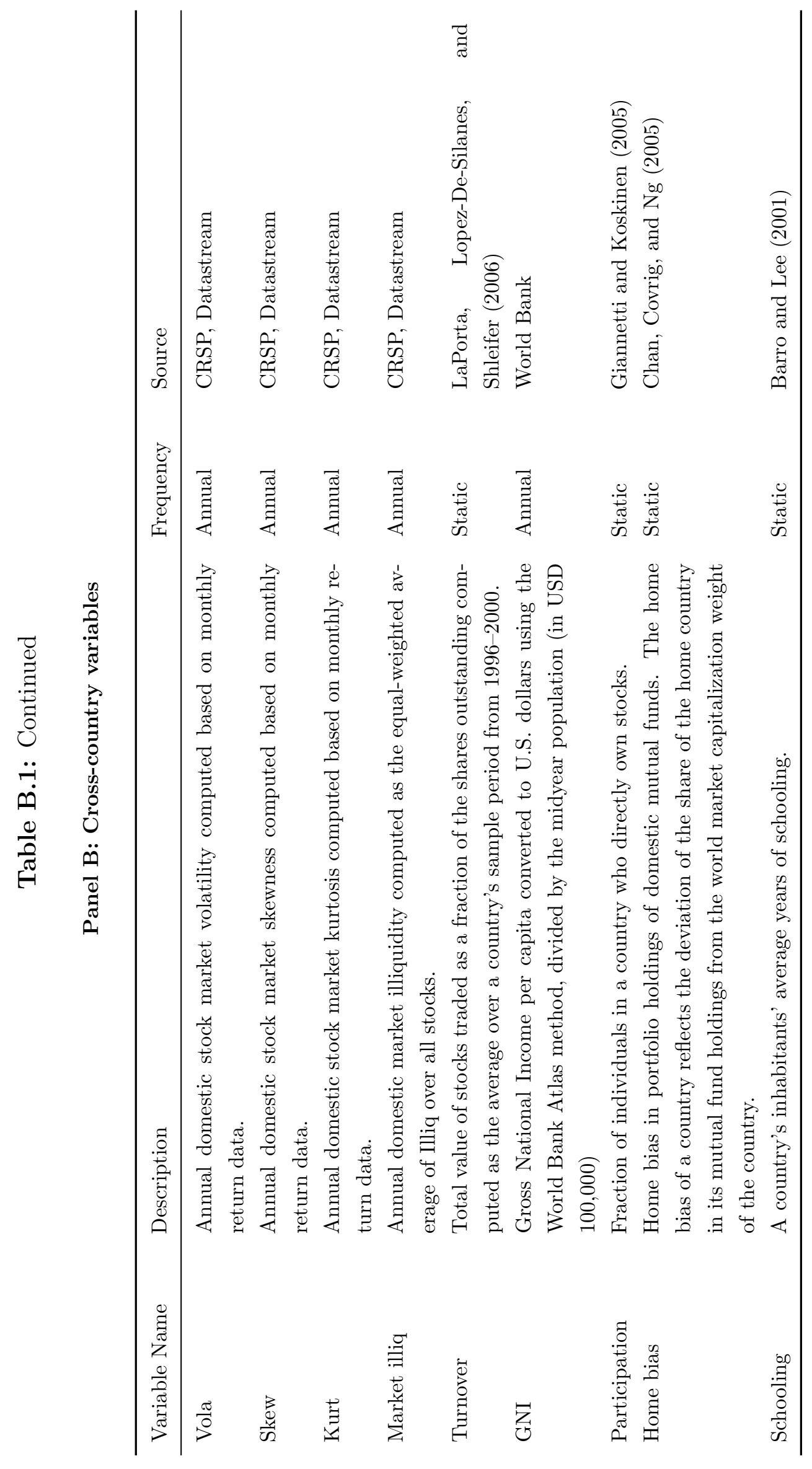




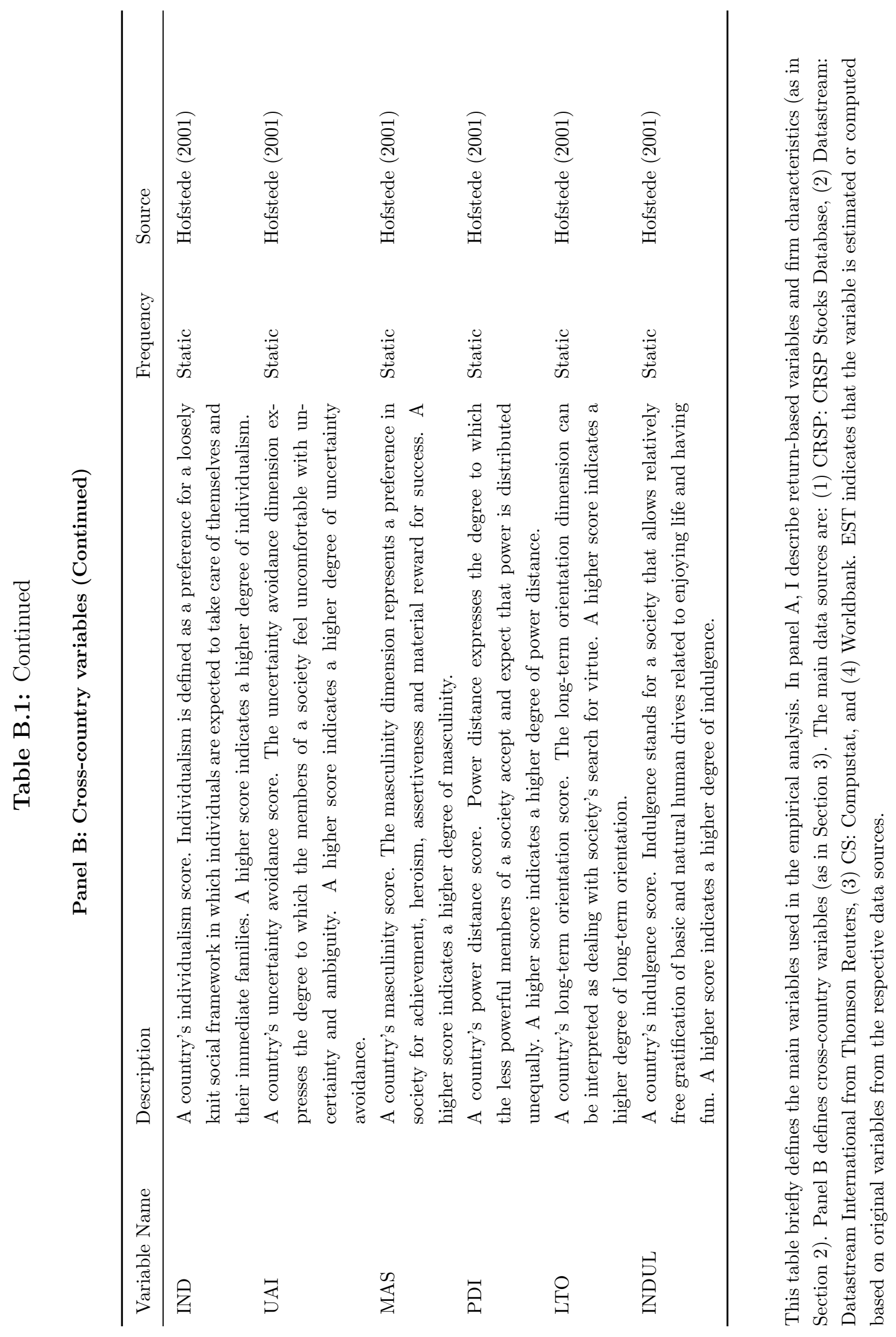




\section{References}

Amihud, Y., 2002. Illiquidity and stock returns: cross-section and time-series effects. Journal of Financial Markets 5:31-56.

Ang, A., and J. Chen. 2002. Asymmetric correlations of equity portfolios. Journal of Financial Economics 63:443-94.

Ang, A., and J. Chen. 2007. CAPM over the long-run: 1926-2001. Journal of Empirical Finance 14:1-40.

Ang, A., J. Chen, and Y. Xing. 2006. Downside risk. Review of Financial Studies 19:1191239.

Ang, A., R. J. Hodrick, Y. Xing, and X. Zhang. 2006. The cross-section of volatility and expected returns. Journal of Finance 61:259-99.

Ang, A., R. J. Hodrick, Y. Xing, and X. Zhang. 2009. High idiosyncratic volatility and low returns: international and further U.S. evidence. Journal of Financial Economics 91:1-23.

Ang, A., J. Liu, and K. Schwarz. 2010. Using stocks or portfolios in tests of factor models. Unpublished Working Paper, Columbia University and University of Pennsylvania.

Asness, C., T. Moskowitz, and L. H. Pedersen. 2013. Value and momentum everywhere. Journal of Finance 68:929-85.

Bali, T. G., and N. Cakici. 2008. Idiosyncratic volatility and the cross-section of expected returns. Journal of Financial and Quantitative Analysis 43:29-58.

Bali, T. G., N. Cakici, and R. F. Whitelaw. 2014. Hybrid tail risk and expected stock returns: When does the tail wag the dog? Review of Asset Pricing Studies 4:206-46.

Bali, T. G., K. O. Demirtas, and H. Levy. 2009. Is there an intertemporal relation between downside risk and expected returns? Journal of Financial and Quantitative Analysis 44:883-909.

Banz, R., 1981. The relation between return and market value of common stocks. Journal of Financial Economics 9:3-18.

Barro, R., 2006. Rare disasters and asset markets in the twentieth century. Quarterly Journal of Economics 121:823-66. 
Barro, R., 2009. Rare disasters, asset prices, and welfare costs. American Economic Review 99:243-64.

Barro, R. J., and J.-W. Lee. 2001. International data on educational attainment: Updates and implications. Oxford Economic Papers 53:541-63.

Basu, S. 1983. The relationship between earnings yield, market value, and return for NYSE common stocks: further evidence. Journal of Financial Economics 12:129-56.

Bates, D.S. 2000. Post 87 crash fears in the S\&P 500 futures options market. Journal of Econometrics 94:181-238.

Bollerslev, T., and V. Todorov. 2011. Tails, fears, and risk premia. Journal of Finance $66: 2165-211$.

Carhart, M. 1997. On persistence in mutual fund performance. Journal of Finance 52:57-82.

Chabi-Yo, F., S. Ruenzi, and F. Weigert. 2015. Crash Sensitivity and the cross-section of expected stock returns. Unpublished Working Paper, Ohio State University, University of Mannheim, and University of St. Gallen.

Chan, K., V. Covrig, and L. Ng. 2005. What determines the domestic bias and foreign bias? Evidence from mutual fund equity allocations worldwide. Journal of Finance 60:1495-534.

Cholette, L., and C.-C. Lu. 2011. The market premium for dynamic tail risk. Unpublished Working Paper, University of Stavanger and National Chengchi University.

Chui, A. C. W., S. Titman, and K. C. J. Wei. 2010. Individualism and momentum around the world. Journal of Finance 65:361-92.

Embrechts, P., A. McNeil, and D. Straumann. 2002. Correlation and dependence in risk management: Properties and pitfalls. In Risk management: Value at risk and beyond, 176-223. Ed. M. A. H. Dempster. Cambridge: Cambridge University Press.

Fama, E. F., and K. R. French. 1992. The cross-section of expected stock returns. Journal of Finance 47:427-65.

Fama, E. F., and K. R. French. 1993. Common risk factors in the returns on stocks and bonds. Journal of Financial Economics 33:3-56.

Fama, E. F., and K. R. French. 1998. Value versus growth: the international evidence. Journal of Finance 53:1975-99. 
Fama, E. F., and J. D. MacBeth. 1973. Risk, return, and equilibrium: Empirical tests. Journal of Political Economy 81:607-36.

French, K.R., Poterba, J.M., 1991. Investor diversification and international equity markets. American Economic Review 81:222-6.

Frijns, B., A. Gilbert, T. Lehnert, and A. Tourani-Rad. 2013. Uncertainty avoidance, risk tolerance and corporate takeover decisions. Journal of Banking and Finance 37:2457-71.

Gabaix, X. 2012. Variable rare disasters: An exactly solved framework for ten puzzles in macro-finance. Quarterly Journal of Economics 127, 645-700.

Galsband, V. 2012. Downside risk of international stock returns. Journal of Banking and Finance 36:2379-88.

Genest, C., K. Ghoudi, and L. P. Rivest. 1995. A semiparametric estimation procedure of dependence parameters in multivariate families of distributions. Biometrika 82:543-52.

Gennaioli, N., A. Shleifer, and R. Vishney. 2015. Neglected risks: The psychology of financial crises. Unpublished Working Paper, Bocconi University, University of Chicago, and Harvard University.

Giannetti, M., and Y. Koskinen. 2005. Investor protection and demand for equity. Unpublished Working Paper, Stockholm School of Economics.

Griffin, J. M. 2002. Are the Fama and French factors global or country specific? Review of Financial Studies 15:783-803.

Griffin, J. M., X. Ji, and J. S. Martin. 2003. Momentum investing and business cycle risk: Evidence from pole to pole. Journal of Finance 58:2515-47.

Guiso, L., P. Sapienza, and L. Zingales. 2008. Trusting the stock market. Journal of Finance 63:2557-600.

Guiso, L., and M. Paiella. 2008. Risk aversion, wealth, and background risk. Journal of the European Economic Association 6:1109-50.

Harvey, C. R., and A. Siddique. 2000. Conditional skewness in asset pricing tests. Journal of Finance 55:1263-95.

Hofstede, G. 2001. Culture's consequences: Comparing values, behaviors, institutions, and organizations across nations, 2nd ed. Beverly Hills, CA: Sage Publication. 
Hou, K., G. A. Karolyi, and B.-C. Kho. 2011. What factors drive global stock returns. Review of Financial Studies 24:2527-74.

Hsee, C. K., and E. U. Weber. 1999. Cross-national differences in risk preference and lay predictions. Journal of Behavioral Decision Making 12:165-79.

Ince, O. S., and R. B. Porter. 2006. Individual equity return data from Thomson Datastream: Handle with care! Journal of Financial Research 29:463-79.

Jalal, A., and M. Rockinger. 2008. Predicting tail-related risk measures: the consequences of using GARCH filters for non GARCH data. Journal of Empirical Finance 5:868-77.

Jegadeesh, N., and S. Titman. 1993. Returns to buying winners and selling losers: implications for stock market efficiency. Journal of Finance 48:65-91.

Julliard, C., and A. Ghosh. 2012. Can rare events explain the equity premium puzzle? Review of Financial Studies 25:3037-76.

Kelly, B., and H. Jiang. 2014. Tail risk and asset prices. Review of Financial Studies 27:284171.

Kothari, S. P., J. Shanken, and R. G. Sloan. 1995. Another look at the cross section of expected stock returns. Journal of Finance 50:185-224.

La Porta, R., F. Lopez-De-Silanes, and A. Shleifer. 2006. What works in securities laws? Journal of Finance 61:1-32.

Lesmond, D. A., J. P. Ogden, and C. A. Trzcinka. 1999. A new estimate of transaction costs. Review of Financial Studies 12:1113-41.

Lewellen, J., and S. Nagel. 2006. The conditional CAPM does not explain asset-pricing anomalies. Journal of Financial Economics 82:89-314.

Lintner, J. 1965. The valuation of risk assets and the selection of risky investments in stock portfolios and capital budgets. Review of Economics and Statistics 47:13-37.

McNeil, A. J., R. Frey, and P. Embrechts. 2005. Quantitative risk management. Princeton: Princeton University Press.

Newey, W. K., and K. D. West. 1987. A simple positive semi-definite, heteroskedasticity and autocorrelation consistent covariance matrix. Econometrica 55:703-708. 
Paravisini, D., V. Rappoport, and E. Ravina. 2015. Risk aversion and wealth: Evidence from person-person lending portfolios. Unpublished Working Paper, London School of Economics and Columbia University.

Poon, S. H., M. Rockinger, and J. Tawn. 2004. Extreme value dependence in financial markets: diagnostics, models, and financial implications. Review of Financial Studies 17:581610.

Rietz, T. A. 1988. The equity risk premium: A solution. Journal of Monetary Economics 22:117-31.

Rieger, M. O., M. Wang, and T. Hens. 2015. Risk preferences around the world. Management Science 61:637-48.

Rouwenhorst, K. G. 1998. International momentum strategies. Journal of Finance 53:267-84.

Roy, A. D. 1952. Safety First and the holdings of assets. Econometrica 20:431-49.

Rubinstein, M. 1994. Implied binomial trees. Journal of Finance 49:771-813.

Sibuya, M. 1960. Bivariate extreme statistics. Annals of the Institute of Statistical Mathematics 11:195-210.

Sharpe, W. F. 1964. Capital asset prices: A theory of market equilibrium under conditions of risk. Journal of Finance 19:425-42.

Sklar, A. 1959. Fonctions de répartition à $n$ dimensions et leurs marges. Publications de l'Institut de Statistique de l'Université de Paris 14:229-31.

Statman, M. 2008. Countries and culture in behavioral finance. CFA Institute Conference Proceedings Quarterly.

Tanaka, T., C. F. Camerer, and Q. Nguyen. 2010. Risk and time preferences: Linking experimental and household survey data from Vietnam. American Economic Review 100:557-71.

Tawn, J. 1988. Bivariate extreme value theory: models and estimation. Biometrika 75:397415.

Van Oordt, M. R. K., and C. Zhou. Forthcoming. Systematic tail risk. Journal of Financial and Quantitative Analysis.

Weber, E. U., and C. K. Hsee. 1998. Cross-National differences in risk perception, but crosscultural similarities in attitudes towards perceived risk. Management Science 44:1205-17. 
Figure 1: Different copula dependence structures

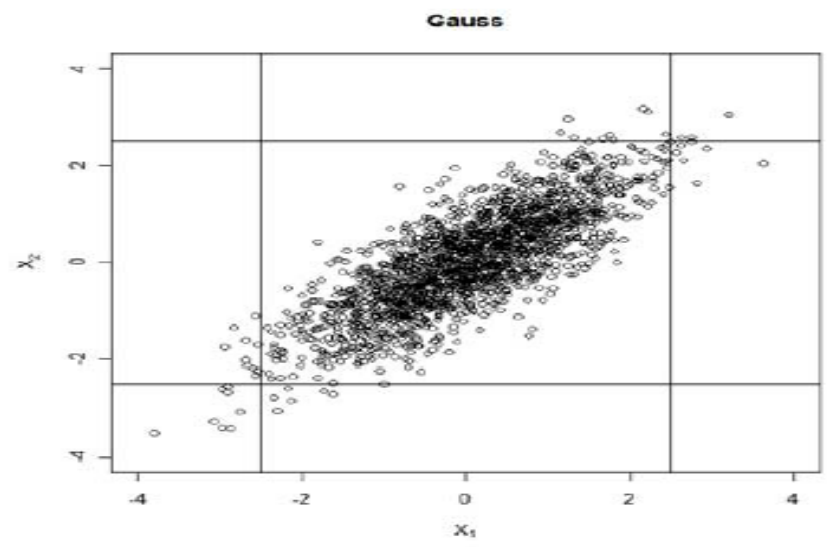

(a) No extreme dependence

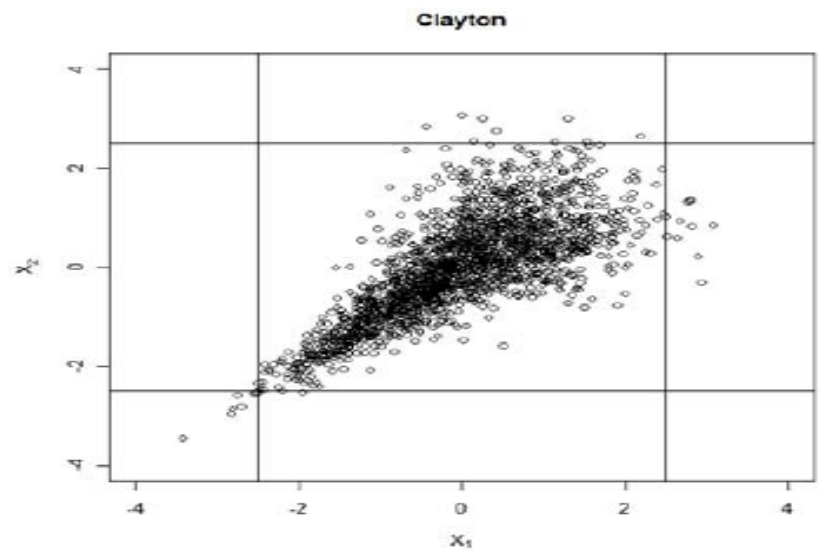

(b) LTD

This figure displays 2,000 random variates from two bivariate distributions with standard normal marginal distributions and dependence structures exhibiting either no extreme dependence (panel A) or extreme dependence in the lower left tail, that is, LTD (panel B). In each case, the linear correlation is set to 0.8. 
Figure 2: Aggregate LTD and UTD over time

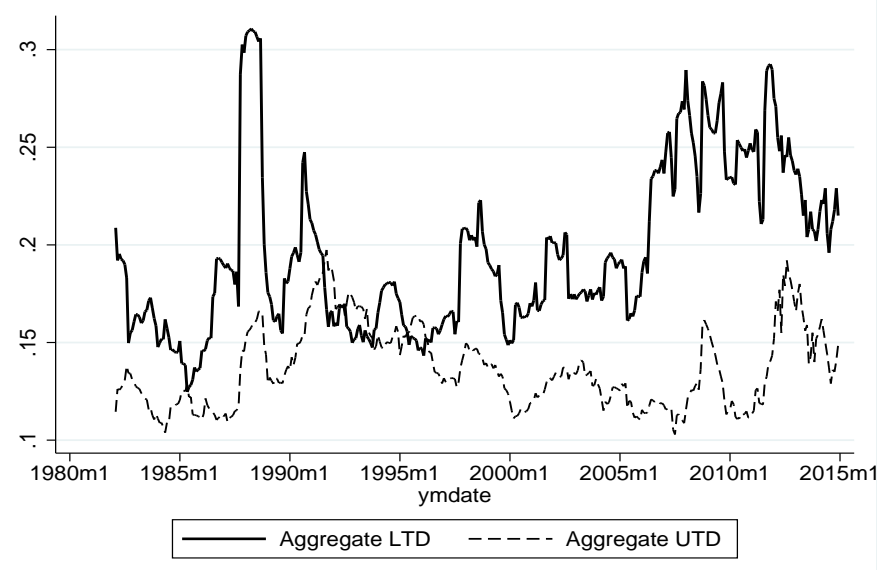

(a) Worldwide aggregate LTD and UTD

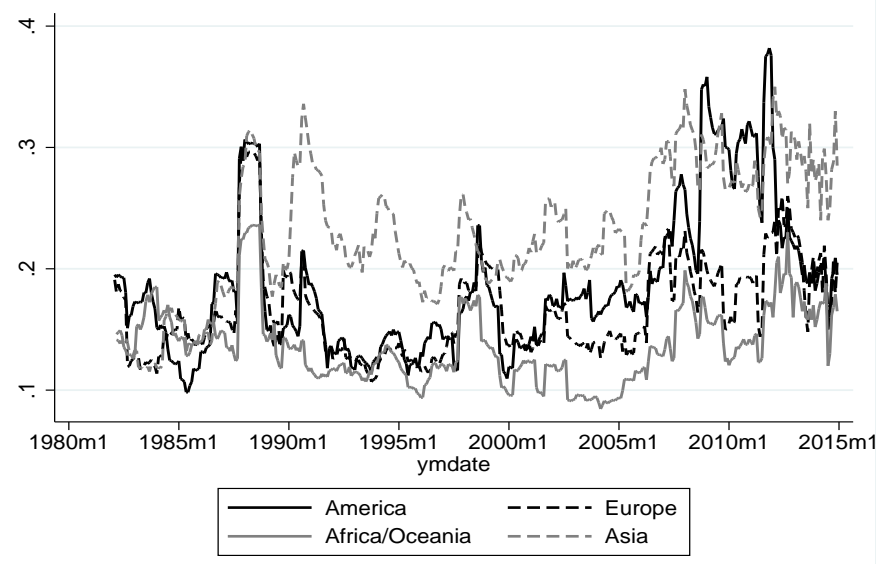

(b) Aggregate LTD: Continents

Panel A of this figure displays the evolution of worldwide aggregate LTD and worldwide aggregate UTD over time. Worldwide aggregate LTD $\left(\mathrm{LTD}_{m, t}\right)$ is defined as the monthly cross-sectional, equal-weighted, average of $\operatorname{LTD}_{i, t}$ over all stocks $i$ in all countries in our sample. Worldwide aggregate UTD $\left(\mathrm{UTD}_{m, t}\right)$ is defined as the monthly cross-sectional, equal-weighted, average of $\mathrm{UTD}_{i, t}$ over all stocks $i$ in all countries in my sample. Panel B displays the development of aggregate LTD subdivided by geographical regions. The sample covers forty international countries with a maximum sample period from January 1981 to December 2014. 


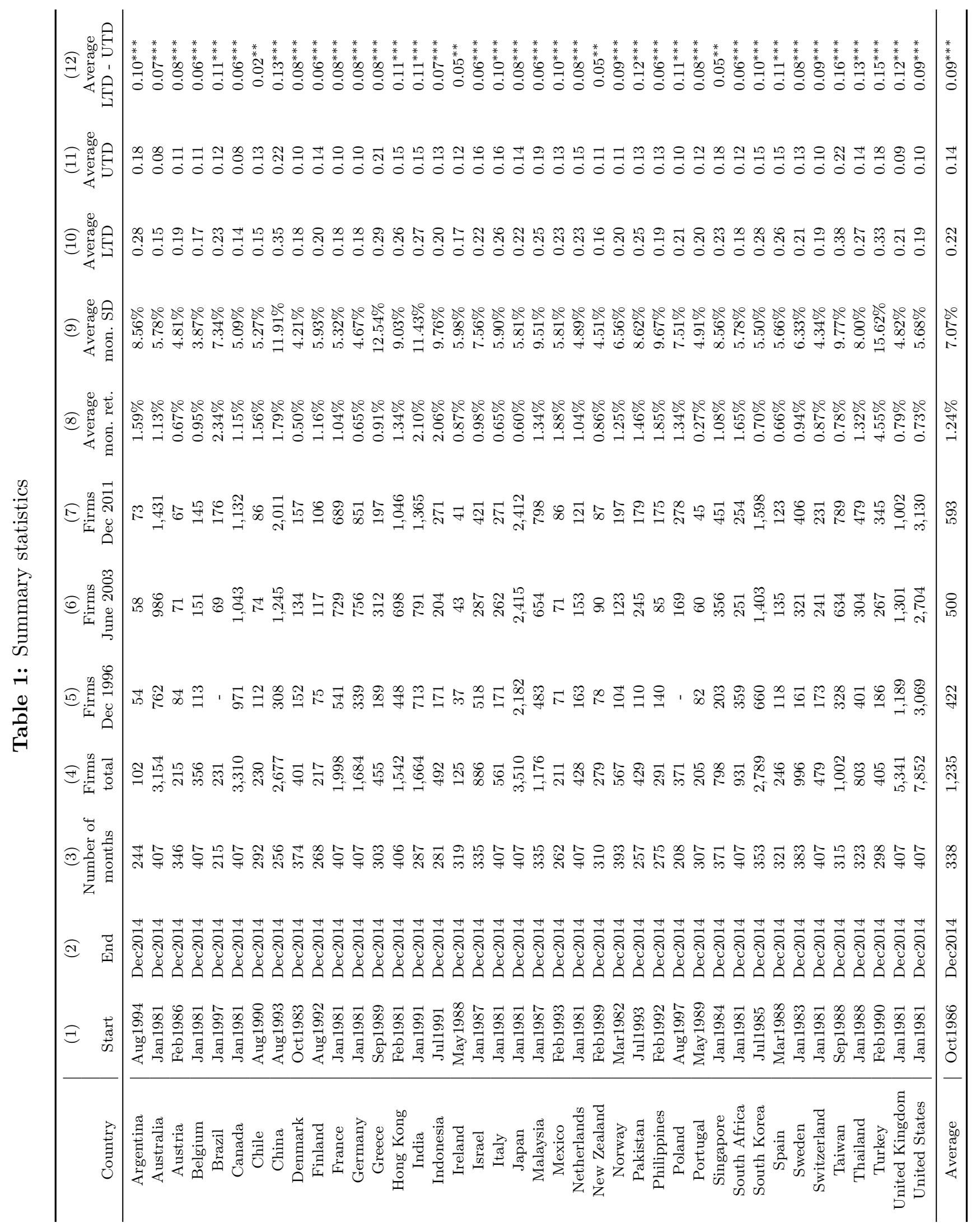


Table 1: continued

This table reports summary statistics of individual stocks from forty markets around the world. Except for the U.S. market data, all data is collected from the Thomson Reuters Datastream database. The U.S. market data is collected from the CRSP database. I only include common stocks (both domestic and foreign stocks) that are listed on the major exchanges in each country. Columns (1)-(3) report the start date, end date, and length of the sample period for each country. In Columns (4)-(7), I provide summary statistics of the total number of different stocks, the number of different stocks in December 1996, the number of different stocks in June 2003, and the number of different stocks in December 2011. Columns (8) and (9) display the average equal-weighted monthly return and volatility per country. Finally, in Columns (10)-(12), I report the average equal-weighted LTD, UTD, and the LTD - UTD difference for all stocks per country. The maximum sample period is from January 1981 to December 2014. $t$-statistics are in parentheses. ${ }^{* * *}$, **, and ${ }^{*}$ indicate significance at the $1 \%, 5 \%$, and $10 \%$ level, respectively. 
Table 2: LTD returns during crisis periods

\begin{tabular}{|c|c|c|c|c|}
\hline Country & $\begin{array}{c}(2) \\
\text { Mean } \\
\text { crisis return }\end{array}$ & $\begin{array}{l}(3) \\
\text { Strong } \\
\text { LTD }\end{array}$ & $\begin{array}{c}(4) \\
\text { Weak } \\
\text { LTD }\end{array}$ & $\begin{array}{c}(5) \\
\text { Strong - } \\
\text { Weak }\end{array}$ \\
\hline rgentina & $17.10 \%$ & $-23.65 \%$ & $-7.82 \%$ & $-15.84 \%^{* * *}(-8.78)$ \\
\hline Australia & $11.23 \%$ & $-16.78 \%$ & $-9.32 \%$ & $-7.46 \%$ *** $(-5.67)$ \\
\hline Austria & $-16.10 \%$ & $-19.50 \%$ & $-4.51 \%$ & $-14.99 \%^{* * *}(-12.61)$ \\
\hline Belgium & $-12.92 \%$ & $-13.89 \%$ & $-4.37 \%$ & $-9.52 \%^{* * *}(-9.73)$ \\
\hline Brazil & $-20.14 \%$ & $-22.41 \%$ & $-8.62 \%$ & $-13.79 \% * * *(-6.89)$ \\
\hline Canada & $-9.83 \%$ & $-14.23 \%$ & $-7.91 \%$ & $-6.32 \%^{* * *}(-7.46)$ \\
\hline Chile & $-8.99 \%$ & $-9.87 \%$ & $-3.45 \%$ & $-7.79 \% * * *(-4.51)$ \\
\hline China & $-21.34 \%$ & $-22.43 \%$ & $-16.73 \%$ & $-5.70 \%^{* *}(-3.81)$ \\
\hline Denmark & $-11.45 \%$ & $-15.65 \%$ & $-5.89 \%$ & $-9.76 \%$ *** $(-7.65)$ \\
\hline Finland & $-12.45 \%$ & $-14.31 \%$ & $-4.67 \%$ & $-9.64 \%^{* * *}(-5.31)$ \\
\hline France & $-11.45 \%$ & $-14.51 \%$ & $-6.01 \%$ & $-8.50 \%$ *** $(-9.75)$ \\
\hline Germany & $-12.91 \%$ & $-15.15 \%$ & $-5.04 \%$ & $-10.11 \%^{* * *}(-18.11)$ \\
\hline Greece & $-19.32 \%$ & $-20.43 \%$ & $-10.67 \%$ & $-9.76 \%^{* * *}(-6.01)$ \\
\hline Hong Kong & $-17.65 \%$ & $-21.65 \%$ & $-12.45 \%$ & $-9.20 \%$ *** $(-6.54)$ \\
\hline India & $-17.98 \%$ & $-24.11 \%$ & $-15.31 \%$ & $-8.80 \%$ *** $(-5.61)$ \\
\hline Indonesia & $-19.78 \%$ & $-21.34 \%$ & $-7.90 \%$ & $-13.44 \%^{* * *}(-4.68)$ \\
\hline Ireland & $-14.31 \%$ & $-16.55 \%$ & $-7.65 \%$ & $-8.90 \%$ *** $(-4.31)$ \\
\hline Israel & -16 & $-21.34 \%$ & $-11.56 \%$ & $-9.78 \% * * *(-5.70)$ \\
\hline Italy & $-13.45 \%$ & $-14.00 \%$ & $-6.78 \%$ & $-7.22 \%^{* * *}(-11.87)$ \\
\hline Japan & $-12.34 \%$ & $-15.31 \%$ & $-8.11 \%$ & $-7.20 \%^{* * *}(-7.21)$ \\
\hline Malays & $-16.89 \%$ & $-21.45 \%$ & $-12.43 \%$ & $-9.02 \%^{* * *}(-4.76)$ \\
\hline $\mathrm{Me}$ & -14 & -18 & $-6.12 \%$ & $-12.52 \% * * *(-5.91)$ \\
\hline Netherlands & $-12.54 \%$ & $-15.65 \%$ & $-7.11 \%$ & $-8.54 \%^{* * *}(-11.01)$ \\
\hline New Zealand & $-8.45 \%$ & $-8.99 \%$ & $-4.10 \%$ & $-4.89 \%^{* * *}(-3.21)$ \\
\hline Norway & $-16.54 \%$ & $-20.01 \%$ & $-9.12 \%$ & $-10.89 \%^{* * *}(-10.56)$ \\
\hline Pakistan & $-20.14 \%$ & $-23.45 \%$ & $-7.34 \%$ & $-16.11 \%^{* * *}(-6.01)$ \\
\hline Philippines & $-13.89 \%$ & $-16.45 \%$ & $-12.45 \%$ & $-4.00 \%^{* * *}(-3.10)$ \\
\hline Poland & $-11.02 \%$ & $-14.56 \%$ & $-8.76 \%$ & $-5.80 \% * *(-2.56)$ \\
\hline Portugal & $-9.43 \%$ & $-12.01 \%$ & $-4.11 \%$ & $-7.90 \%$ *** $(-6.02)$ \\
\hline Singapore & $-14.31 \%$ & $-19.31 \%$ & $-10.43 \%$ & $-8.88 \%$ *** $(-6.89)$ \\
\hline South Afri & $-11.67 \%$ & $-14.51 \%$ & $-5.61 \%$ & $-8.90 \%$ *** $(-5.12)$ \\
\hline South Korea & $-15.61 \%$ & $-17.65 \%$ & $-8.11 \%$ & $-9.54 \%$ *** $(-6.41)$ \\
\hline Spain & $-10.87 \%$ & $-13.45 \%$ & $-6.87 \%$ & $-6.58 \% * * *(-5.43)$ \\
\hline Sweden & $-13.54 \%$ & $-16.45 \%$ & $-9.34 \%$ & $-7.11 \%^{* * *}(-9.21)$ \\
\hline Switzerland & $-12.07 \%$ & $-15.10 \%$ & $-5.13 \%$ & $-9.97 \% * * *(-10.01)$ \\
\hline Taiwan & $-17.21 \%$ & $-17.32 \%$ & $-14.31 \%$ & $-3.01 \%^{* *}(-2.43)$ \\
\hline Thailand & $-18.76 \%$ & $-22.45 \%$ & $-9.45 \%$ & $-13.00 \%^{* * *}(-6.78)$ \\
\hline Turkey & $-22.67 \%$ & $-25.89 \%$ & $-17.56 \%$ & $-8.33 \%^{* * *}(-5.57)$ \\
\hline United Kingdom & $-10.12 \%$ & $-13.56 \%$ & $-8.22 \%$ & $-5.34 \%^{* * *}(-6.54)$ \\
\hline United States & $-10.21 \%$ & $-15.31 \%$ & $-5.67 \%$ & $-9.64 \%$ *** $(-6.57)$ \\
\hline Average & $-14.42 \%$ & $-17.48 \%$ & $-8.43 \%$ & $-9.05 \%$ *** $(-6.91)$ \\
\hline
\end{tabular}

This table reports equal-weighted monthly returns of stocks sorted by realized LTD during crisis periods. Each month $t$, I rank stocks into quintiles (1-5) based on their estimated LTD over the past 12 months and form equal-weighted portfolios at the beginning of each monthly period. I investigate realized monthly returns of the strong LTD portfolio (portfolio 5), the weak LTD portfolio (portfolio 1) and the strong weak LTD portfolio during periods of market crashes in the respective countries. I define periods as market crashes if the local value-weighted market return is below its $5 \%$ percentile. The sample covers data from common stocks in forty markets all over the world. The maximum sample period is from January 1981 to December 2014 . $t$-statistics are in parentheses. ${ }^{* * *},{ }^{* *}$, and ${ }^{*}$ indicate significance at the $1 \%, 5 \%$, and $10 \%$ level, respectively. 
Table 3: LTD and realized stock returns worldwide

Panel A: Equal-weighted univariate sorts: LTD and local currency returns

\begin{tabular}{c|ccccccc}
\hline Portfolio & $\begin{array}{c}\text { Worldwide } \\
\text { (incl. U.S.) }\end{array}$ & United States & $\begin{array}{c}\text { Worldwide } \\
\text { (excl. U.S.) }\end{array}$ & America & Europe & Oceania & Asia \\
\hline 1 Weak LTD & $14.53 \%$ & $10.89 \%$ & $16.43 \%$ & $11.84 \%$ & $14.54 \%$ & $17.75 \%$ & $18.34 \%$ \\
2 & $16.67 \%$ & $13.56 \%$ & $18.90 \%$ & $15.02 \%$ & $17.72 \%$ & $19.53 \%$ & $19.03 \%$ \\
3 & $19.61 \%$ & $16.87 \%$ & $18.52 \%$ & $16.67 \%$ & $18.93 \%$ & $19.32 \%$ & $20.05 \%$ \\
4 & $18.21 \%$ & $19.68 \%$ & $20.05 \%$ & $19.94 \%$ & $20.00 \%$ & $24.67 \%$ & $20.45 \%$ \\
5 Strong LTD & $21.88 \%$ & $22.43 \%$ & $22.88 \%$ & $22.76 \%$ & $22.34 \%$ & $26.17 \%$ & $22.90 \%$ \\
\hline Strong - Weak & $7.35 \%^{* * *}$ & $11.54 \%^{* * *}$ & $6.45 \%^{* * *}$ & $10.92 \%^{* * *}$ & $7.80 \%^{* * *}$ & $8.32 \%^{* * *}$ & $4.56 \%^{*}$ \\
& $(3.79)$ & $(4.51)$ & $(3.61)$ & $(3.41)$ & $(3.12)$ & $(3.58)$ & $(1.91)$ \\
\hline
\end{tabular}

Panel B: Value-weighted univariate sorts: LTD and local currency returns

\begin{tabular}{c|ccccccc}
\hline Portfolio & $\begin{array}{c}\text { Worldwide } \\
\text { (incl. U.S.) }\end{array}$ & Unites States & $\begin{array}{c}\text { Worldwide } \\
\text { (excl. U.S.) }\end{array}$ & America & Europe & Oceania & Asia \\
\hline 1 Weak LTD & $5.93 \%$ & $2.89 \%$ & $8.51 \%$ & $4.39 \%$ & $10.62 \%$ & $10.93 \%$ & $7.84 \%$ \\
2 & $6.85 \%$ & $4.87 \%$ & $9.41 \%$ & $5.51 \%$ & $11.39 \%$ & $13.15 \%$ & $7.95 \%$ \\
3 & $6.88 \%$ & $7.12 \%$ & $9.25 \%$ & $6.95 \%$ & $11.82 \%$ & $13.04 \%$ & $6.62 \%$ \\
4 & $8.95 \%$ & $9.85 \%$ & $11.49 \%$ & $7.52 \%$ & $12.48 \%$ & $14.39 \%$ & $8.40 \%$ \\
5 Strong LTD & $12.74 \%$ & $12.67 \%$ & $14.12 \%$ & $13.92 \%$ & $15.72 \%$ & $16.25 \%$ & $12.76 \%$ \\
\hline Strong - Weak & $6.81 \%^{* * *}$ & $9.78 \%^{* * *}$ & $5.61 \% * * *$ & $9.53 \% * * *$ & $5.10 \%^{* *}$ & $5.32 \% \%^{* * *}$ & $4.92 \%$ \\
& $(4.89)$ & $(6.12)$ & $(3.54)$ & $(5.23)$ & $(2.05)$ & $(3.07)$ & $(1.56)$ \\
\hline
\end{tabular}

Panel C: Equal-weighted univariate sorts: LTD and USD-denominated returns

\begin{tabular}{c|ccccccc}
\hline Portfolio & $\begin{array}{c}\text { Worldwide } \\
\text { (incl. U.S.) }\end{array}$ & United States & $\begin{array}{c}\text { Worldwide } \\
\text { (excl. U.S.) }\end{array}$ & America & Europe & $\begin{array}{c}\text { Africa/ } \\
\text { Oceania }\end{array}$ & Asia \\
\hline 1 Weak LTD & $15.02 \%$ & $10.89 \%$ & $16.78 \%$ & $12.04 \%$ & $14.56 \%$ & $17.45 \%$ & $18.01 \%$ \\
2 & $17.65 \%$ & $13.56 \%$ & $17.98 \%$ & $14.87 \%$ & $16.02 \%$ & $17.81 \%$ & $18.56 \%$ \\
3 & $18.32 \%$ & $16.87 \%$ & $17.12 \%$ & $15.66 \%$ & $16.57 \%$ & $19.23 \%$ & $18.21 \%$ \\
4 & $19.21 \%$ & $19.68 \%$ & $20.54 \%$ & $18.54 \%$ & $18.03 \%$ & $22.65 \%$ & $19.87 \%$ \\
5 Strong LTD & $21.81 \%$ & $22.43 \%$ & $22.79 \%$ & $22.87 \%$ & $22.10 \%$ & $25.90 \%$ & $22.68 \%$ \\
\hline Strong - Weak & $6.79 \%^{* * *}$ & $11.54 \%^{* * *}$ & $6.01 \%^{* * *}$ & $10.83 \%^{* * *}$ & $7.54 \%^{* * *}$ & $8.45 \%^{* * *}$ & $4.67 \%^{*}$ \\
& $(3.61)$ & $(4.51)$ & $(3.23)$ & $(2.98)$ & $(2.85)$ & $(3.89)$ & $(1.79)$ \\
\hline
\end{tabular}


Table 3: Continued

Panel D: Equal-weighted univariate sorts: LTD and Carhart (1997) four-factor alphas

\begin{tabular}{c|ccccccc}
\hline \multirow{2}{*}{ Portfolio } & Worldwide & \multicolumn{3}{c}{ Worldwide } & \multicolumn{3}{c}{ Africa/ } \\
& (incl. U.S.) & United States & (excl. U.S.) & America & Europe & Oceania & Asia \\
\hline \multirow{2}{*}{1 Weak LTD } & $-2.65 \%^{*}$ & $-3.39 \%^{* *}$ & $-2.21 \%^{*}$ & $-2.35 \%^{*}$ & $-3.10 \%$ & $-1.56 \%$ & $-2.02 \%$ \\
& $(-1.75)$ & $(-2.51)$ & $(-1.70)$ & $-1.76)$ & $(-1.34)$ & $(-1.20)$ & $(-1.03)$ \\
2 & $-1.02 \%$ & $-1.21 \%$ & $-1.65 \%$ & $-2.45 \%$ & $-1.00 \%$ & $-1.95 \%$ & $0.21 \%$ \\
& $(-0.98)$ & $(-0.87)$ & $(-1.34)$ & $(-1.54)$ & $(-0.67)$ & $(-1.15)$ & $(0.06)$ \\
3 & $0.67 \%$ & $0.42 \%$ & $-0.21 \%$ & $0.35 \%$ & $0.24 \%$ & $-1.01 \%$ & $-0.45 \%$ \\
& $(0.56)$ & $(0.54)$ & $(-0.09)$ & $(0.38)$ & $(0.51)$ & $(-0.78)$ & $(-0.34)$ \\
4 & $1.75 \%$ & $2.45 \%$ & $1.45 \%$ & $1.87 \%$ & $1.88 \%$ & $0.32 \%$ & $0.56 \%$ \\
& $(1.23)$ & $(1.43)$ & $(0.98)$ & $(1.06)$ & $(1.24)$ & $(0.67)$ & $(0.56)$ \\
5 Strong LTD & $2.69 \%^{* *}$ & $3.01 \%^{* *}$ & $2.79 \%^{*}$ & $3.75 \%^{* *}$ & $2.77 \%$ & $3.87 \%^{*}$ & $1.99 \%$ \\
& $(2.02)$ & $(2.45)$ & $(1.81)$ & $(2.34)$ & $(1.43)$ & $(1.85)$ & $(1.05)$ \\
\hline \multirow{2}{*}{ Strong - Weak } & $5.34 \%^{* * *}$ & $6.40 \%^{* * *}$ & $5.00 \%^{* * *}$ & $6.10 \%^{* * *}$ & $5.87 \%^{* * *}$ & $5.43 \%^{* *}$ & $4.01 \%$ \\
& $(3.51)$ & $(4.02)$ & $(3.15)$ & $(5.65)$ & $(3.52)$ & $(2.68)$ & $(1.45)$ \\
\hline
\end{tabular}

This table reports results from univariate portfolio sorts based on realized LTD. Panel A of this table reports the results of equal-weighted portfolio sorts of average local currency returns sorted by realized LTD worldwide and for different geographical subsamples. In each month $t$, I sort stocks into five quintiles (1-5) based on realized LTD over the past 12 months, form equal-weighted portfolios at the beginning of each monthly period, and report average returns over the same year. The row labelled "Strong - Weak" reports the difference between the returns of portfolio 5 and portfolio 1 with corresponding statistical significance levels. Panel B reports the results of value-weighted portfolio sorts of average local currency returns sorted by realized LTD worldwide and for different geographical subsamples. Panel C shows the results of equalweighted portfolio sorts of average USD-denominated returns sorted by realized LTD worldwide and for different geographical subsamples. Finally, panel D shows the results of equal-weighted portfolio sorts of average USD-denominated returns adjusted for the Carhart (1997) four-factor alphas worldwide and for different geographical subsamples. Carhart (1997) alphas are estimated based on yearly portfolio and factor returns over the whole sample period using factors for the global region and respective continent/geographical areas, respectively. The sample covers data from common stocks in forty markets all over the world. The maximum sample period is from January 1981 to December 2014. t-statistics are in parentheses. ${ }^{* * *},{ }^{* *}$, and ${ }^{*}$ indicate significance at the $1 \%, 5 \%$, and $10 \%$ level, respectively. 


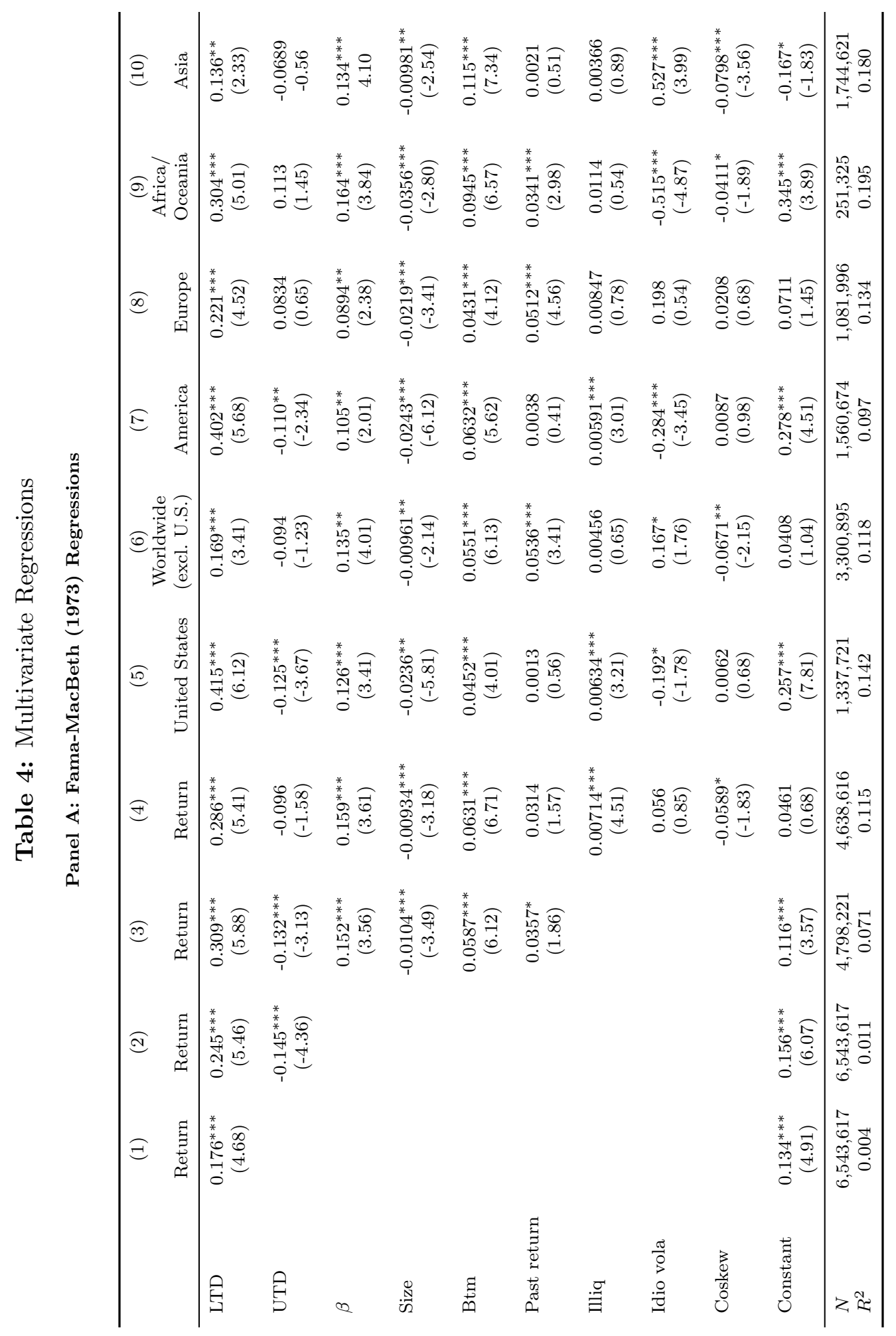


Table 4: Continued

Panel B: Robustness

\begin{tabular}{c|ccccccc}
\hline & Worldwide & & Worldwide & & Africa/ & \\
& (incl. U.S.) & United States & (excl. U.S.) & America & Europe & Oceania & Asia \\
\hline LTD & $0.210^{* * *}$ & $0.345^{* * *}$ & $0.156^{* * *}$ & $0.356^{* * *}$ & $0.204^{* * *}$ & $0.267^{* * *}$ & $0.111^{* *}$ \\
EW market & $(4.67)$ & $(6.01)$ & $(3.23)$ & $(5.01)$ & $(4.02)$ & $(4.71)$ & $(2.25)$ \\
LTD & $0.198^{* * *}$ & $0.311^{* * *}$ & $0.167^{* * *}$ & $0.387^{* * *}$ & $0.210^{* * *}$ & $0.287^{* * *}$ & $0.123^{* *}$ \\
MSCI local & $(4.01)$ & $(5.71)$ & $(3.37)$ & $(5.46)$ & $(3.45)$ & $(4.82)$ & $(2.31)$ \\
LTD & $0.167^{* * *}$ & $0.287^{* * *}$ & $0.141^{* * *}$ & $0.341^{* * *}$ & $0.178^{* * *}$ & $0.231^{* *}$ & $0.084^{*}$ \\
MSCI world & $(3.65)$ & $(4.67)$ & $(2.95)$ & $(4.56)$ & $(2.61)$ & $(4.02)$ & $(1.74)$ \\
& & & & & & & \\
LTD & $0.265^{* * *}$ & $0.401^{* * *}$ & $0.162^{* * *}$ & $0.399^{* * *}$ & $0.206^{* * *}$ & $0.285^{* * *}$ & $0.117^{* *}$ \\
Copula (1)-(B)-(I) & $(5.40)$ & $(6.31)$ & $(3.35)$ & $(4.98)$ & $(4.21)$ & $(4.68)$ & $(2.40)$ \\
LTD & $0.251^{* * *}$ & $0.367^{* * *}$ & $0.151^{* * *}$ & $0.371^{* * *}$ & $0.213^{* * *}$ & $0.294^{* * *}$ & $0.104^{* *}$ \\
Copula (2)-(B)-(I) & $(5.01)$ & $(5.63)$ & $(3.21)$ & $(5.24)$ & $(4.35)$ & $(4.73)$ & $(2.01)$ \\
LTD & $0.245^{* * *}$ & $0.381^{* * *}$ & $0.169^{* * *}$ & $0.354^{* * *}$ & $0.225^{* * *}$ & $0.273^{* * *}$ & $0.095^{*}$ \\
Copula (3)-(B)-(IV) & $(4.59)$ & $(5.78)$ & $(3.40)$ & $(5.19)$ & $(4.61)$ & $(4.36)$ & $(1.80)$ \\
LTD & $0.226^{* * *}$ & $0.341^{* * *}$ & $0.134^{* * *}$ & $0.385^{* * *}$ & $0.195^{* * *}$ & $0.268^{* * *}$ & $0.091^{*}$ \\
Copula (4)-(D)-(IV) & $(4.51)$ & $(5.57)$ & $(3.04)$ & $(5.36)$ & $(4.01)$ & $(4.21)$ & $(1.74)$ \\
\hline Downside beta & $0.0582^{* *}$ & $0.0634^{* *}$ & $0.0341^{* *}$ & $0.0601^{* * *}$ & $0.0391^{*}$ & $0.0467^{* *}$ & 0.0054 \\
$\beta^{-}$ & $(2.56)$ & $(2.41)$ & $(2.23)$ & $(3.01)$ & $(1.82)$ & $(2.45)$ & $(0.65)$ \\
\hline
\end{tabular}

This table displays the results of multivariate Fama and MacBeth (1973) regressions. In panel A, I display the results of monthly Fama and MacBeth (1973) regressions of one-year returns on LTD, UTD, beta $(\beta)$, the log of market capitalization (Size), book-to-market ratio (Btm), past returns, illiquidity (Illiq), idiosyncratic volatility (Idio Vola), coskewness (Coskew), and downside beta $\left(\beta^{-}\right)$for the pooled worldwide sample and for different geographical subsamples. Definitions of all risk- and firm characteristics are listed in panel A of Table B.1 in the Appendix. All risk characteristics are calculated contemporaneously to the yearly return. Regressions (1)-(4) refer to the pooled worldwide sample. Regressions (5)-(10) report the results of regression (5) for different geographical subsamples. In panel B, I report the results of regression (4) from panel A; I only report the coefficient estimates for the impact of LTD and truncate all control variable coefficients. I report results when (1) I apply different market returns for the estimation of LTD, (ii) use ex ante randomly selected copulas for the estimation of LTD, and use $\beta^{-}$instead of LTD as our measure of crash sensitivity. The sample covers data from common stocks in forty markets all over the world. The maximum sample period is from January 1981 to December 2014. $t$-statistics are in parentheses. ${ }^{* * *},{ }^{* *}$, and ${ }^{*}$ indicate significance at the $1 \%, 5 \%$, and $10 \%$ level, respectively. 
Table 5: Time-varying crash aversion of investors

\begin{tabular}{lcc}
\hline & $\begin{array}{c}\text { Post }- \\
\text { market crash }\end{array}$ & $\begin{array}{c}\text { Remaining } \\
\text { years }\end{array}$ \\
\hline Worldwide & $0.456^{* * *}$ & $0.251^{* * *}$ \\
(incl. U.S.) & $(4.76)$ & $(5.61)$ \\
United States & $0.751^{* * *}$ & $0.325^{* * *}$ \\
& $(6.59)$ & $(6.30)$ \\
Worldwide & $0.267^{* * *}$ & $0.141^{* * *}$ \\
(excl. U.S.) & $(3.24)$ & $(3.31)$ \\
America & $0.713^{* * *}$ & $0.179^{* * *}$ \\
& $(6.04)$ & $(5.41)$ \\
Europe & $0.401^{* * *}$ & $0.156^{* * *}$ \\
& $(3.89)$ & $(4.72)$ \\
Africa / & $0.361^{* * *}$ & $0.204^{* * *}$ \\
Oceania & $(4.62)$ & $(4.33)$ \\
Asia & 0.140 & 0.089 \\
& $(1.41)$ & $(1.19)$ \\
\hline
\end{tabular}

This table presents the results of multivariate Fama and MacBeth (1973) regressions of one-year returns on LTD and other control variables as in regression (4) of Table 4 for the pooled worldwide sample and for different geographical areas. We provide results for two subsamples: the "Post - Market Crash" subsample containing the three subsequent years after an extreme market downturn has occurred and the "Remaining Years" subsample. We define "extreme market downturns" as the three worst return months for each country in our sample. I only report the coefficient estimate for the impact of LTD. All other explanatory variables are included in the regressions, but their coefficient estimates are suppressed. The sample covers data from common stocks in forty markets all over the world. The maximum sample period is from January 1981 to December 2014 . $t$-statistics are in parentheses. ${ }^{* * *},{ }^{* *}$, and ${ }^{*}$ indicate significance at the $1 \%, 5 \%$, and $10 \%$ level, respectively. 
Table 6: LTD premium per country

\begin{tabular}{|c|c|c|c|c|}
\hline Country & $\begin{array}{c}(1) \\
\text { Strong } \\
\text { LTD }\end{array}$ & $\begin{array}{c}(2) \\
\text { Weak } \\
\text { LTD }\end{array}$ & $\begin{array}{l}(3) \\
\text { Strong - } \\
\text { Weak }\end{array}$ & $\begin{array}{l}(4) \\
\text { FMB } \\
\text { LTD Estimate }\end{array}$ \\
\hline Argentina & $33.56 \%$ & $24.51 \%$ & $9.05 \% *(1.87)$ & $0.524^{* * *}(3.00)$ \\
\hline Australia & $25.41 \%$ & $14.78 \%$ & $10.63 \%^{* * *}(3.51)$ & $0.432^{* * *}(4.62)$ \\
\hline Austria & $13.78 \%$ & $12.94 \%$ & $0.84 \%(0.21)$ & $0.102(1.02)$ \\
\hline Belgium & $19.21 \%$ & $11.79 \%$ & $7.42 \%^{* *}(2.41)$ & $0.286^{* * *}(3.92)$ \\
\hline Brazil & $45.10 \%$ & $44.78 \%$ & $0.32 \%(0.01)$ & $-0.145(-0.45)$ \\
\hline Canada & $24.51 \%$ & $14.92 \%$ & $9.59 \%$ *** (4.02) & $0.461^{* * *}(5.23)$ \\
\hline Chile & $30.45 \%$ & $31.23 \%$ & $-0.78 \%(-0.21)$ & $0.085(0.72)$ \\
\hline China & $25.42 \%$ & $27.99 \%$ & $-2.57 \%(-0.92)$ & $-0.201(-1.04)$ \\
\hline Denmark & $13.45 \%$ & $9.21 \%$ & $4.24 \%(1.23)$ & $0.254^{* *}(2.34)$ \\
\hline Finland & $21.76 \%$ & $14.78 \%$ & $6.98 \%^{* *}(2.10)$ & $0.314^{* *}(2.16)$ \\
\hline France & $22.19 \%$ & $14.57 \%$ & $7.62 \%^{* *}(2.03)$ & $0.352^{* * *}(3.74)$ \\
\hline Germany & $17.92 \%$ & $8.31 \%$ & $9.61 \% * * *(3.41)$ & $0.382^{* * *}(3.46)$ \\
\hline Greece & $41.08 \%$ & $39.21 \%$ & $1.87 \%(0.56)$ & $0.245^{*}(1.76)$ \\
\hline Hong Kong & $27.00 \%$ & $24.12 \%$ & $2.88 \%(0.97)$ & $0.104(1.13)$ \\
\hline India & $40.32 \%$ & $38.97 \%$ & $1.35 \%(0.54)$ & $0.201(1.45)$ \\
\hline Indonesia & $40.76 \%$ & $35.12 \%$ & $5.64 \%(1.30)$ & $0.165^{*}(1.80)$ \\
\hline Ireland & $15.12 \%$ & $13.24 \%$ & $1.88 \%(0.65)$ & $0.094(1.21)$ \\
\hline Israel & $19.32 \%$ & $16.54 \%$ & $2.78 \%(1.05)$ & $0.243^{*}(1.84)$ \\
\hline Italy & $18.32 \%$ & $9.23 \%$ & $9.09 \%^{* *}(2.26)$ & $0.329^{* *}(2.28)$ \\
\hline Japan & $12.65 \%$ & $7.24 \%$ & $5.41 \%^{* *}(2.14)$ & $0.342^{* * *}(3.76)$ \\
\hline Malaysia & $21.65 \%$ & $15.23 \%$ & $6.42 \%^{*}(1.80)$ & $-0.032(-0.23)$ \\
\hline Mexico & $29.54 \%$ & $27.31 \%$ & $2.23 \%(0.59)$ & $0.177(1.53)$ \\
\hline Netherlands & $20.43 \%$ & $10.80 \%$ & $9.63 \%^{* * *}(3.67)$ & $0.501^{* * *}(5.63)$ \\
\hline New Zealand & $17.45 \%$ & $13.79 \%$ & $3.66 \% *(1.80)$ & $0.329^{* *}(2.40)$ \\
\hline Norway & $29.56 \%$ & $20.54 \%$ & $9.02 \% * *(2.05)$ & $0.309^{* * *}(2.97)$ \\
\hline Pakistan & $23.01 \%$ & $22.05 \%$ & $0.96 \%(0.39)$ & $0.083(1.02)$ \\
\hline Philippines & $31.89 \%$ & $32.67 \%$ & $-0.78 \%(-0.29)$ & $-0.121(-0.63)$ \\
\hline Poland & $32.19 \%$ & $29.42 \%$ & $2.77 \%(0.57)$ & $0.304(1.26)$ \\
\hline Portugal & $12.81 \%$ & $3.49 \%$ & $9.32 \%^{* *}(2.19)$ & $0.314^{* *}(2.22)$ \\
\hline Singapore & $22.74 \%$ & $15.71 \%$ & $7.03 \% * *(2.50)$ & $0.128(0.97)$ \\
\hline South Africa & $29.10 \%$ & $25.44 \%$ & $3.66 \%(1.05)$ & $0.167(0.85)$ \\
\hline South Korea & $23.76 \%$ & $26.03 \%$ & $-2.27 \%(-0.68)$ & $0.031(0.18)$ \\
\hline Spain & $10.43 \%$ & $10.10 \%$ & $0.33 \%(0.05)$ & $-0.015(-0.21)$ \\
\hline Sweden & $22.90 \%$ & $13.45 \%$ & $9.45 \%^{* *}(2.37)$ & $0.395^{* * *}(4.51)$ \\
\hline Switzerland & $16.43 \%$ & $9.84 \%$ & $6.59 \% * *(2.41)$ & $0.264^{* * *}(3.20)$ \\
\hline Taiwan & $11.45 \%$ & $13.06 \%$ & $-1.61 \%(-0.61)$ & $-0.110(-0.66)$ \\
\hline Thailand & $26.91 \%$ & $22.45 \%$ & $4.46 \%(1.17)$ & $0.201^{*}(1.76)$ \\
\hline Turkey & $57.12 \%$ & $55.60 \%$ & $1.52 \%(0.40)$ & $0.367(1.09)$ \\
\hline United Kingdom & $20.71 \%$ & $10.79 \%$ & $9.92 \%^{* * *}(4.37)$ & $0.379^{* * *}(5.42)$ \\
\hline United States & $22.43 \%$ & $10.89 \%$ & $11.54 \%^{* * *}(4.51)$ & $0.402^{* * *}(5.68)$ \\
\hline
\end{tabular}

This table presents the results of equal-weighted univariate portfolio sorts with local currency returns based on realized LTD and Fama and MacBeth (1973) regressions of yearly firm returns on LTD and different risk and firm characteristics for each country in my sample. Column (1) and Column (2) report the average yearly return for the top and bottom quintile LTD portfolios. Column (3) shows the return difference for the strong - weak LTD portfolios and column (4) reports the coefficient estimate for LTD in the multivariate regression setup (4) from panel A of Table 4 for each country. The sample covers data from common stocks in forty markets all over the world. The maximum sample period is from January 1981 to December 2014. $t$-statistics are in parentheses. ${ }^{* * *},{ }^{* *}$, and ${ }^{*}$ indicate significance at the $1 \%, 5 \%$, and $10 \%$ level, respectively. 
Table 7: Cross-country determinants

\begin{tabular}{|c|c|c|c|c|}
\hline & $\begin{array}{c}\text { Stock market } \\
\text { characteristics } \\
(1) \\
\text { LTD } \\
\text { premium }\end{array}$ & $\begin{array}{c}\text { Investor } \\
\text { characteristics } \\
(2) \\
\text { LTD } \\
\text { premium }\end{array}$ & $\begin{array}{l}\text { Cultural } \\
\text { attitudes } \\
(3) \\
\text { LTD } \\
\text { premium }\end{array}$ & $\begin{array}{c}\text { Final } \\
(4) \\
\text { LTD } \\
\text { premium }\end{array}$ \\
\hline Vola & $\begin{array}{l}0.682 \\
(1.21)\end{array}$ & & & \\
\hline Skew & $\begin{array}{c}-0.0256^{*} \\
(-1.85)\end{array}$ & & & $\begin{array}{c}-0.0197^{*} \\
(-1.72)\end{array}$ \\
\hline Kurt & $\begin{array}{c}0.00732 \\
(0.32)\end{array}$ & & & \\
\hline Market illiq & $\begin{array}{c}-0.0154 \\
-0.56\end{array}$ & & & \\
\hline Turnover & $\begin{array}{c}-0.00045 \\
(-0.75)\end{array}$ & & & \\
\hline GNI & & $\begin{array}{c}0.231^{* * *} \\
(3.57)\end{array}$ & & $\begin{array}{l}0.192^{*} \\
(1.88)\end{array}$ \\
\hline Participation & & $\begin{array}{c}0.0799 \\
(0.61)\end{array}$ & & \\
\hline Home bias & & $\begin{array}{c}0.00341 \\
(1.05)\end{array}$ & & \\
\hline Schooling & & $\begin{array}{c}0.00832 \\
(0.62)\end{array}$ & & \\
\hline IND & & & $\begin{array}{c}0.00143^{* * *} \\
(2.99)\end{array}$ & $\begin{array}{c}0.000876^{* *} \\
(2.01)\end{array}$ \\
\hline UAI & & & $\begin{array}{c}0.000512 \\
(0.82)\end{array}$ & \\
\hline PDI & & & $\begin{array}{c}0.000321 \\
(0.63)\end{array}$ & \\
\hline MAS & & & $\begin{array}{c}-0.000721 \\
(-1.21)\end{array}$ & \\
\hline LTO & & & $\begin{array}{c}0.0000065 \\
(0.01)\end{array}$ & \\
\hline INDUL & & & $\begin{array}{c}0.000671 \\
(1.34)\end{array}$ & \\
\hline Constant & $\begin{array}{c}0.0782^{* *} \\
(2.31)\end{array}$ & $\begin{array}{c}-0.0312 \\
(-0.56)\end{array}$ & $\begin{array}{c}-0.0612 \\
(-1.24)\end{array}$ & $\begin{array}{c}-0.00742 \\
(-1.36)\end{array}$ \\
\hline$N$ & 1,059 & 662 & 1,072 & 1,033 \\
\hline$R^{2}$ & 0.121 & 0.239 & 0.117 & 0.116 \\
\hline
\end{tabular}

This table displays the results of pooled OLS regressions with yearly time dummies and clustered standard errors by country of the LTD premium on cross-country explanatory variables. I regress the return difference between top quintile LTD stocks and weak quintile LTD stocks in country $i$ in year $y$ on country-specific stock market characteristics (Vola, Skew, Kurt, Market illiq, and Turnover), investor characteristics (GNI, Participation, Home bias, and Schooling), and cultural attitudes (IND, UAI, PDI, MAS, LTO, and INDUL). Definitions of all cross-country variables (and the respective frequency and origin) are reported in panel B of Table B.1 in the Appendix. The sample covers data from common stocks in forty markets all over the world. The maximum sample period is from January 1981 to December 2014. $t$-statistics are in parentheses. ${ }^{* * *},{ }^{* *}$, and ${ }^{*}$ indicate significance at the $1 \%, 5 \%$, and $10 \%$ level, respectively. 
Table 8: LTD and future stock returns worldwide

Panel A: Equal-weighted predictive univariate sorts with local currency returns

\begin{tabular}{|c|c|c|c|c|c|c|c|}
\hline Portfolio & $\begin{array}{l}\text { Worldwide } \\
\text { (incl. U.S.) }\end{array}$ & United States & $\begin{array}{l}\text { Worldwide } \\
\text { (excl. U.S.) }\end{array}$ & America & Europe & $\begin{array}{l}\text { Africa/ } \\
\text { Oceania }\end{array}$ & Asia \\
\hline 1 Weak LTD & $0.91 \%$ & $0.66 \%$ & $0.97 \%$ & $0.68 \%$ & $0.87 \%$ & $0.96 \%$ & $1.02 \%$ \\
\hline 2 & $1.05 \%$ & $0.71 \%$ & $1.06 \%$ & $0.72 \%$ & $0.81 \%$ & $1.00 \%$ & $0.98 \%$ \\
\hline 3 & $1.04 \%$ & $0.79 \%$ & $1.10 \%$ & $0.81 \%$ & $0.87 \%$ & $1.12 \%$ & $1.08 \%$ \\
\hline 4 & $1.15 \%$ & $0.89 \%$ & $1.34 \%$ & $0.85 \%$ & $1.20 \%$ & $1.32 \%$ & $1.25 \%$ \\
\hline 5 Strong LTD & $1.20 \%$ & $1.11 \%$ & $1.24 \%$ & $1.11 \%$ & $1.16 \%$ & $1.22 \%$ & $1.16 \%$ \\
\hline Strong - Weak & $\begin{array}{l}0.29 \% \\
(1.52)\end{array}$ & $\begin{array}{c}0.45 \% * * * \\
(3.52)\end{array}$ & $\begin{array}{l}0.27 \% \\
(1.30)\end{array}$ & $\begin{array}{c}0.43 \% * * * \\
(2.98)\end{array}$ & $\begin{array}{l}0.29 \% \\
(1.57)\end{array}$ & $\begin{array}{l}0.26 \% \\
(1.45)\end{array}$ & $\begin{array}{l}0.14 \% \\
(0.76)\end{array}$ \\
\hline
\end{tabular}

Panel B: Value-weighted predictive univariate sorts with local currency returns

\begin{tabular}{|c|c|c|c|c|c|c|c|}
\hline Portfolio & $\begin{array}{l}\text { Worldwide } \\
\text { (incl. U.S.) }\end{array}$ & United States & $\begin{array}{l}\text { Worldwide } \\
\text { (excl. U.S.) }\end{array}$ & America & Europe & $\begin{array}{l}\text { Africa/ } \\
\text { Oceania }\end{array}$ & Asia \\
\hline 1 Weak LTD & $0.64 \%$ & $0.30 \%$ & $0.67 \%$ & $0.31 \%$ & $0.61 \%$ & $0.64 \%$ & $0.79 \%$ \\
\hline 2 & $0.65 \%$ & $0.34 \%$ & $0.61 \%$ & $0.36 \%$ & $0.69 \%$ & $0.68 \%$ & $0.78 \%$ \\
\hline 3 & $0.68 \%$ & $0.39 \%$ & $0.68 \%$ & $0.38 \%$ & $0.69 \%$ & $0.67 \%$ & $0.78 \%$ \\
\hline 4 & $0.80 \%$ & $0.51 \%$ & $0.79 \%$ & $0.50 \%$ & $0.75 \%$ & $0.82 \%$ & $0.81 \%$ \\
\hline 5 Strong LTD & $0.92 \%$ & $0.66 \%$ & $0.90 \%$ & $0.65 \%$ & $0.90 \%$ & $0.83 \%$ & $0.83 \%$ \\
\hline Strong - Weak & $\begin{array}{l}0.28 \% \\
(1.32)\end{array}$ & $\begin{array}{c}0.36 \% * * * \\
(3.14)\end{array}$ & $\begin{array}{l}0.23 \% \\
(1.20)\end{array}$ & $\begin{array}{c}0.34 \% * * * \\
(3.01)\end{array}$ & $\begin{array}{l}0.29 \% \\
(1.45)\end{array}$ & $\begin{array}{l}0.19 \% \\
(1.02)\end{array}$ & $\begin{array}{l}0.04 \% \\
(0.05)\end{array}$ \\
\hline
\end{tabular}

Panel C: Equal-weighted predictive univariate sorts with USD-denominated returns

\begin{tabular}{|c|c|c|c|c|c|c|c|}
\hline Portfolio & $\begin{array}{l}\text { Worldwide } \\
\text { (incl. U.S.) }\end{array}$ & United States & $\begin{array}{l}\text { Worldwide } \\
\text { (excl. U.S.) }\end{array}$ & America & Europe & $\begin{array}{l}\text { Africa/ } \\
\text { Oceania }\end{array}$ & Asia \\
\hline 1 Weak LTD & $0.92 \%$ & $0.66 \%$ & $0.98 \%$ & $0.67 \%$ & $0.87 \%$ & $0.94 \%$ & $1.03 \%$ \\
\hline 2 & $1.00 \%$ & $0.71 \%$ & $1.05 \%$ & $0.73 \%$ & $0.82 \%$ & $1.01 \%$ & $1.01 \%$ \\
\hline 3 & $1.07 \%$ & $0.79 \%$ & $1.12 \%$ & $0.82 \%$ & $0.88 \%$ & $1.11 \%$ & $1.06 \%$ \\
\hline 4 & $1.20 \%$ & $0.89 \%$ & $1.32 \%$ & $0.85 \%$ & $1.19 \%$ & $1.30 \%$ & $1.23 \%$ \\
\hline 5 Strong LTD & $1.20 \%$ & $1.11 \%$ & $1.25 \%$ & $1.11 \%$ & $1.17 \%$ & $1.20 \%$ & $1.16 \%$ \\
\hline Strong - Weak & $\begin{array}{l}0.28 \% \\
(1.48)\end{array}$ & $\begin{array}{c}0.45 \% \text { *** } \\
(3.52)\end{array}$ & $\begin{array}{l}0.27 \% \\
(1.28)\end{array}$ & $\begin{array}{c}0.44 \% * * * \\
(3.01)\end{array}$ & $\begin{array}{l}0.28 \% \\
(1.49)\end{array}$ & $\begin{array}{l}0.26 \% \\
(1.38)\end{array}$ & $\begin{array}{l}0.13 \% \\
(0.65)\end{array}$ \\
\hline
\end{tabular}

Panel D: Equal-weighted predictive sorts: Carhart (1997) four-factor alphas

\begin{tabular}{c|ccccccc}
\hline Portfolio & $\begin{array}{c}\text { Worldwide } \\
\text { (incl. U.S.) }\end{array}$ & United States & $\begin{array}{c}\text { Worldwide } \\
\text { (excl. U.S.) }\end{array}$ & America & Europe & $\begin{array}{c}\text { Africa/ } \\
\text { Oceania }\end{array}$ & Asia \\
\hline \multirow{2}{*}{1 Weak LTD } & $-0.10 \%$ & $-0.14 \%$ & $-0.08 \%$ & $-0.13 \%$ & $-0.09 \%$ & $-0.03 \%$ & $-0.04 \%$ \\
& $(-1.02)$ & $(-1.32)$ & $(-0.65)$ & $(-1.26)$ & $(-1.10)$ & $(-0.07)$ & $(-0.24)$ \\
2 & $-0.02 \%$ & $-0.00 \%$ & $0.01 \%$ & $0.02 \%$ & $-0.01 \%$ & $0.03 \%$ & $-0.02 \%$ \\
& $(-0.43)$ & $(0.02)$ & $(0.05)$ & $(0.13)$ & $(-0.08)$ & $(0.14)$ & $(-0.06)$ \\
3 & $0.06 \%$ & $0.08 \%$ & $0.05 \%$ & $0.07 \%$ & $0.05 \%$ & $0.00 \%$ & $0.03 \%$ \\
& $(0.23)$ & $(0.21)$ & $(0.06)$ & $(0.16)$ & $(0.35)$ & $(0.08)$ & $(0.29)$ \\
4 & $0.14 \%$ & $0.15 \%$ & $0.11 \%$ & $0.17 \%$ & $0.07 \%$ & $0.04 \%$ & $0.05 \%$ \\
5 Strong LTD & $(0.89)$ & $(1.25)$ & $(1.21)$ & $(1.41)$ & $(0.56)$ & $(0.31)$ & $(0.2)$ \\
& $0.15 \%$ & $0.20 \% *$ & $0.15 \%$ & $0.21 \%$ & $0.18 \%$ & $0.10 \%$ & $0.07 \%$ \\
& $(1.41)$ & $(1.88)$ & $(1.30)$ & $(1.60)$ & $(1.32)$ & $(0.79)$ & $(0.68)$ \\
\hline \multirow{2}{*}{ Strong - Weak } & $0.25 \%$ & $0.34 \% * *$ & $0.23 \%$ & $0.34 \% * *$ & $0.27 \%$ & $0.13 \%$ & $0.11 \%$ \\
& $(1.37)$ & $(2.58)$ & $(1.30)$ & $(2.47)$ & $(1.54)$ & $(1.09)$ & $(0.54)$ \\
\hline
\end{tabular}




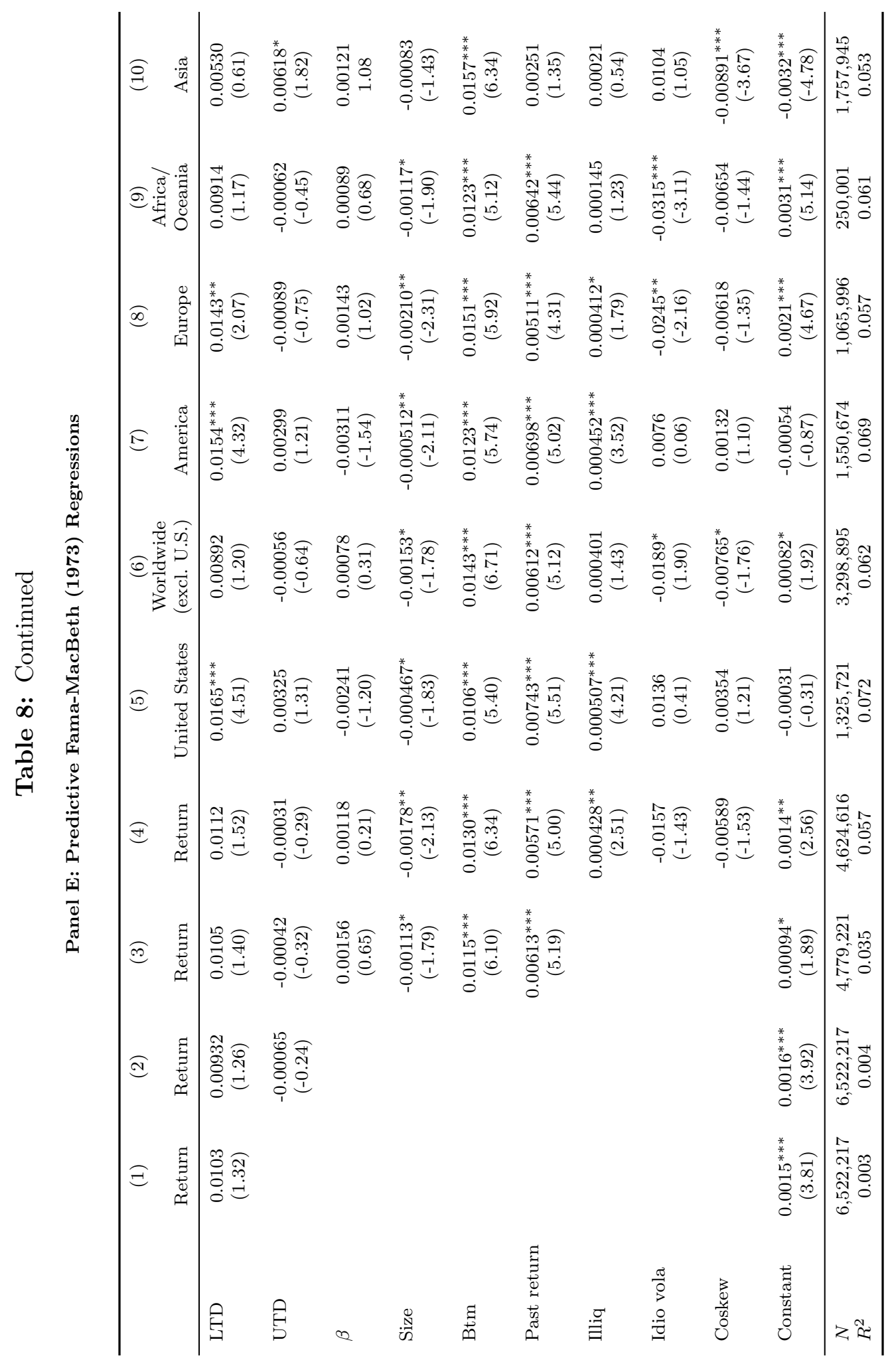


Table 8: Continued

This table reports results from predictive univariate portfolio sorts and Fama and MacBeth (1973) regressions. Panel A of this table reports the results of equal-weighted predictive portfolio sorts of average local currency returns sorted by LTD worldwide and for different geographical subsamples. In each month $t$, I sort stocks into five quintiles (1-5) based on LTD over the past 12 months. I then report average future monthly returns in month $t+1$ of the quintile portfolios as well as the "Strong - Weak" difference return with corresponding statistical significance levels. In panels B-D, I report the results of value-weighted predictive sorts, equalweighted predictive sorts with USD-denominated returns, and equal-weighted predictive sorts adjusted for the international international four-factor Carhart (1997) model. Finally, panel E shows the results of Fama and MacBeth (1973) regressions of future monthly returns on LTD and other risk- and firm characteristics again for the pooled worldwide sample and for different geographical subsamples. The sample covers data from common stocks in forty markets all over the world. The maximum sample period is from January 1981 to December 2014. $t$-statistics are in parentheses. ${ }^{* * *},{ }^{* *}$, and ${ }^{*}$ indicate significance at the $1 \%, 5 \%$, and $10 \%$ level, respectively. 
Table 9: LTD and future stock returns worldwide - A refinement

Panel A: Equal-weighted predictive sorts with local currency returns (Excl. high volatility stocks)

\begin{tabular}{c|ccccccc}
\hline Portfolio & $\begin{array}{c}\text { Worldwide } \\
\text { (incl. U.S.) }\end{array}$ & United States & $\begin{array}{c}\text { Worldwide } \\
\text { (excl. U.S.) }\end{array}$ & America & Europe & $\begin{array}{c}\text { Africa/ } \\
\text { Oceania }\end{array}$ & Asia \\
\hline 1 Weak LTD & $0.87 \%$ & $0.63 \%$ & $0.92 \%$ & $0.64 \%$ & $0.84 \%$ & $0.92 \%$ & $0.96 \%$ \\
2 & $1.02 \%$ & $0.70 \%$ & $1.03 \%$ & $0.73 \%$ & $0.85 \%$ & $1.03 \%$ & $1.02 \%$ \\
3 & $1.16 \%$ & $0.76 \%$ & $1.13 \%$ & $0.78 \%$ & $0.91 \%$ & $1.06 \%$ & $1.08 \%$ \\
4 & $1.14 \%$ & $0.92 \%$ & $1.37 \%$ & $0.92 \%$ & $1.17 \%$ & $1.25 \%$ & $1.26 \%$ \\
5 Strong LTD & $1.27 \%$ & $1.13 \%$ & $1.29 \%$ & $1.13 \%$ & $1.23 \%$ & $1.26 \%$ & $1.23 \%$ \\
\hline Strong - Weak & $0.40 \%^{* *}$ & $0.50 \%^{* * *}$ & $0.37 \%^{* *}$ & $0.49 \%^{* * *}$ & $0.39 \%^{* *}$ & $0.34 \%^{*}$ & $0.27 \%$ \\
& $(2.45)$ & $(3.85)$ & $(2.01)$ & $(3.57)$ & $(2.14)$ & $(1.89)$ & $(1.43)$ \\
\hline
\end{tabular}

Panel B: Value-weighted predictive sorts with local currency returns (Excl. high volatility stocks)

\begin{tabular}{c|ccccccc}
\hline Portfolio & $\begin{array}{c}\text { Worldwide } \\
\text { (incl. U.S.) }\end{array}$ & United States & $\begin{array}{c}\text { Worldwide } \\
\text { (excl. U.S.) }\end{array}$ & America & Europe & $\begin{array}{c}\text { Africa/ } \\
\text { Oceania }\end{array}$ & Asia \\
\hline 1 Weak LTD & $0.58 \%$ & $0.27 \%$ & $0.57 \%$ & $0.28 \%$ & $0.54 \%$ & $0.57 \%$ & $0.72 \%$ \\
2 & $0.64 \%$ & $0.33 \%$ & $0.60 \%$ & $0.32 \%$ & $0.67 \%$ & $0.70 \%$ & $0.70 \%$ \\
3 & $0.67 \%$ & $0.38 \%$ & $0.67 \%$ & $0.38 \%$ & $0.69 \%$ & $0.65 \%$ & $0.71 \%$ \\
4 & $0.78 \%$ & $0.50 \%$ & $0.75 \%$ & $0.49 \%$ & $0.70 \%$ & $0.78 \%$ & $0.74 \%$ \\
5 Strong LTD & $0.94 \%$ & $0.65 \%$ & $0.89 \%$ & $0.66 \%$ & $0.88 \%$ & $0.84 \%$ & $0.82 \%$ \\
\hline Strong - Weak & $0.36 \%^{* *}$ & $0.38 \%^{* * *}$ & $0.32 \%^{* *}$ & $0.38 \%^{* * *}$ & $0.34 \%^{*}$ & $0.27 \% *$ & $0.10 \%$ \\
& $(2.11)$ & $(3.22)$ & $(2.03)$ & $(3.11)$ & $(1.87)$ & $(1.71)$ & $(0.98)$ \\
\hline
\end{tabular}

Panel C: Equal-weighted predictive sorts with USD-denominated returns (Excl. high volatility stocks)

\begin{tabular}{c|ccccccc}
\hline Portfolio & $\begin{array}{c}\text { Worldwide } \\
\text { (incl. U.S.) }\end{array}$ & United States & $\begin{array}{c}\text { Worldwide } \\
\text { (excl. U.S.) }\end{array}$ & America & Europe & $\begin{array}{c}\text { Africa/ } \\
\text { Oceania }\end{array}$ & Asia \\
\hline 1 Weak LTD & $0.88 \%$ & $0.63 \%$ & $0.94 \%$ & $0.64 \%$ & $0.83 \%$ & $0.95 \%$ & $0.99 \%$ \\
2 & $1.04 \%$ & $0.70 \%$ & $1.05 \%$ & $0.71 \%$ & $0.83 \%$ & $1.08 \%$ & $1.04 \%$ \\
3 & $1.15 \%$ & $0.76 \%$ & $1.11 \%$ & $0.77 \%$ & $0.93 \%$ & $1.04 \%$ & $1.10 \%$ \\
4 & $1.16 \%$ & $0.92 \%$ & $1.36 \%$ & $0.92 \%$ & $1.16 \%$ & $1.23 \%$ & $1.24 \%$ \\
5 Strong LTD & $1.27 \%$ & $1.13 \%$ & $1.29 \%$ & $1.13 \%$ & $1.24 \%$ & $1.28 \%$ & $1.25 \%$ \\
\hline \multirow{2}{*}{ Strong - Weak } & $0.39 \%^{* *}$ & $0.50 \%^{* * *}$ & $0.35 \%^{* *}$ & $0.49 \%^{* * *}$ & $0.39 \%^{* *}$ & $0.33 \% *$ & $0.26 \%$ \\
& $(2.34)$ & $(3.85)$ & $(2.24)$ & $(3.46)$ & $(2.01)$ & $(1.82)$ & $(1.32)$ \\
\hline
\end{tabular}

Panel D: Equal-weighted predictive sorts: Carhart (1997) four-factor alphas (Excl. high volatility stocks)

\begin{tabular}{c|ccccccc}
\hline Portfolio & $\begin{array}{c}\text { Worldwide } \\
\text { (incl. U.S.) }\end{array}$ & United States & $\begin{array}{c}\text { Worldwide } \\
\text { (excl. U.S.) }\end{array}$ & America & Europe & $\begin{array}{c}\text { Africa/ } \\
\text { Oceania }\end{array}$ & Asia \\
\hline \multirow{2}{*}{1 Weak LTD } & $-0.13 \%$ & $-0.17 \%$ & $-0.09 \%$ & $-0.16 \%$ & $-0.11 \%$ & $-0.08 \%$ & $-0.04 \%$ \\
& $(-1.21)$ & $(-1.45)$ & $(-0.65)$ & $(-1.29)$ & $(-1.14)$ & $(-0.56)$ & $(-0.29)$ \\
2 & $-0.04 \%$ & $-0.05 \%$ & $0.00 \%$ & $-0.04 \%$ & $-0.02 \%$ & $0.01 \%$ & $0.02 \%$ \\
& $(-0.35)$ & $(-0.45)$ & $(0.05)$ & $(-0.13)$ & $(-0.06)$ & $(0.09)$ & $(0.17)$ \\
3 & $0.07 \%$ & $0.08 \%$ & $0.04 \%$ & $0.09 \%$ & $0.04 \%$ & $0.05 \%$ & $-0.01 \%$ \\
& $(0.17)$ & $(0.23)$ & $(0.23)$ & $(0.25)$ & $(0.11)$ & $(0.08)$ & $(-0.36)$ \\
& $0.15 \%$ & $0.16 \%$ & $0.12 \%$ & $0.18 \%$ & $0.06 \%$ & $0.04 \%$ & $0.03 \%$ \\
& $(1.22)$ & $(1.36)$ & $(1.30)$ & $(1.40)$ & $(0.79)$ & $(0.31)$ & $(0.18)$ \\
5 Strong LTD & $0.19 \%^{*}$ & $0.21 \% * *$ & $0.19 \%$ & $0.21 \% *$ & $0.20 \%$ & $0.18 \%$ & $0.09 \%$ \\
& $(1.73)$ & $(2.01)$ & $(1.51)$ & $(1.79)$ & $(1.41)$ & $(1.39)$ & $(0.78)$ \\
\hline \multirow{2}{*}{ Strong - Weak } & $0.32 \%^{*}$ & $0.38 \% * * *$ & $0.28 \% *$ & $0.37 \% * *$ & $0.31 \% *$ & $0.26 \% *$ & $0.13 \%$ \\
& $(1.91)$ & $(2.88)$ & $(1.72)$ & $(2.51)$ & $(1.90)$ & $(1.73)$ & $(0.78)$ \\
\hline
\end{tabular}




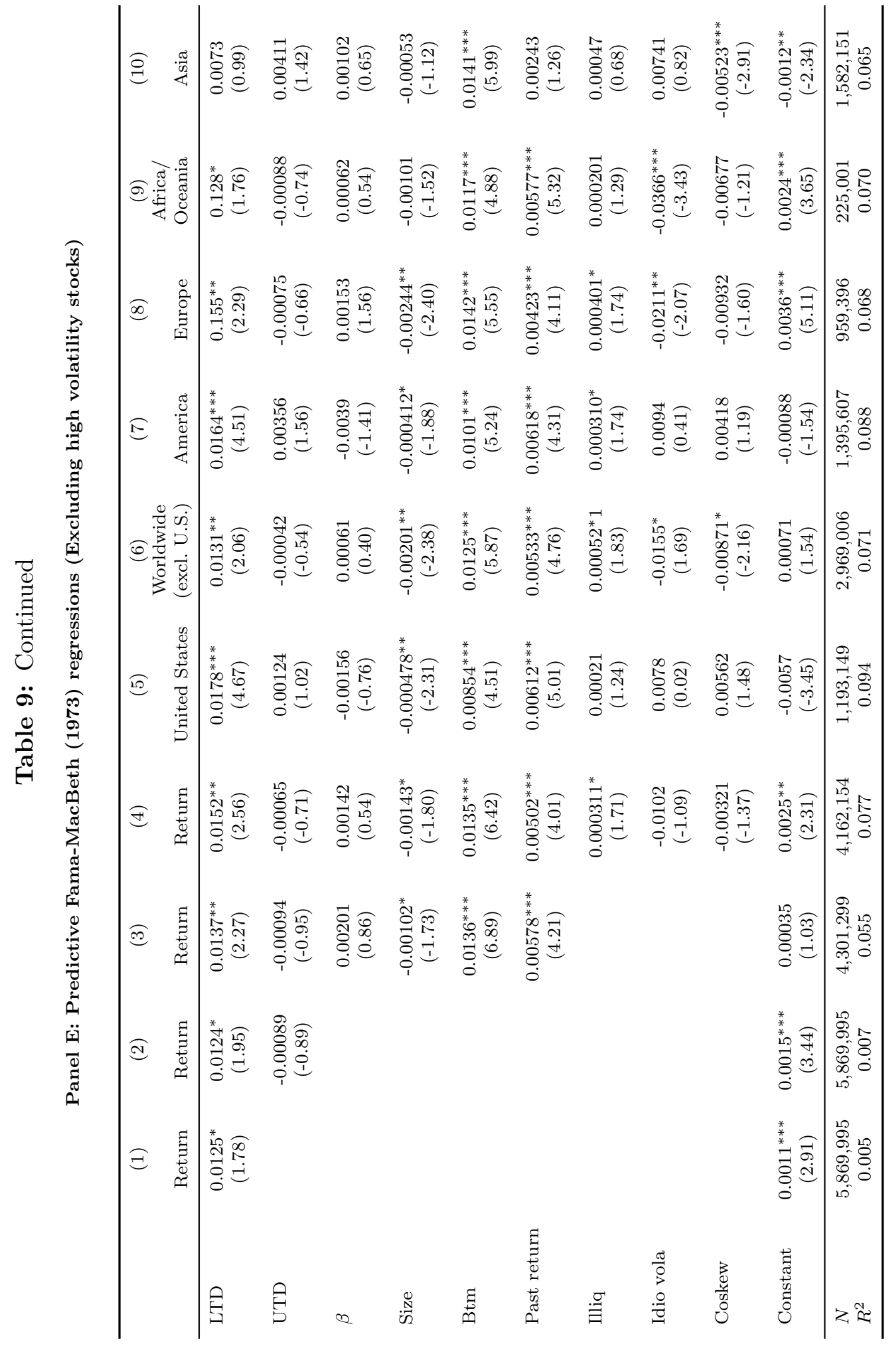


Table 9: Continued

This table reports results from predictive univariate portfolio sorts and Fama and MacBeth (1973) regressions when excluding high volatility stocks from the sample. A stock is classified as highly volatile at month $t$ if its historical one-year standard deviation is in the top decile among all stocks in the respective country. Panel A of this table reports the results of equal-weighted predictive portfolio sorts of average local currency returns sorted by LTD worldwide and for different geographical subsamples. In each month $t$, I sort stocks into five quintiles (1-5) based on LTD over the past 12 months. I then report average future monthly returns in month $t+1$ of the quintile portfolios as well as the "Strong - Weak" difference return with corresponding statistical significance levels. In panels B-D, I report the results of value-weighted predictive sorts, equalweighted predictive sorts with USD-denominated returns, and equal-weighted predictive sorts adjusted for the international international four-factor Carhart (1997) model. Finally, panel E shows the results of Fama and MacBeth (1973) regressions of future monthly returns on LTD and other risk- and firm characteristics again for the pooled worldwide sample and for different geographical subsamples. The sample covers data from common stocks in forty markets all over the world. The maximum sample period is from January 1981 to December 2014. $t$-statistics are in parentheses. ${ }^{* * *},{ }^{* *}$, and ${ }^{*}$ indicate significance at the $1 \%, 5 \%$, and $10 \%$ level, respectively. 